\title{
Does Children's Education Improve Parental Health and Longevity? Causal Evidence from Great Britain*
}

\author{
Cecilia Potente ${ }^{1}$, Patrick Präg ${ }^{2}$, and Christiaan Monden ${ }^{3}$ \\ ${ }^{1}$ Jacobs Center for Productive Youth Development, \\ University of Zurich \\ ${ }^{2}$ CREST, ENSAE, Institut Polytechnique de Paris \\ ${ }^{3}$ Nuffield College and University of Oxford
}

December 6, 2022

\begin{abstract}
Parents with better-educated children are healthier and live longer, but whether there is a causal effect of children's education on their parents' health and longevity is still unclear. First, we demonstrate an association between adults' offspring education and parental mortality in the 1958 British birth cohort study, which remains substantial - about two additional years of life - even when only comparing parents with similar socioeconomic status. Second, we use the 1972 educational reform in England and Wales, which increased the minimum school-leaving age from 15 to 16 years, to identify the presence of a causal effect of children's education on parental health and longevity using census-linked data from the Office for National Statistics Longitudinal Study. Results reveal that children's education has no causal effects on a wide range of parental mortality and
\end{abstract}

${ }^{*}$ This manuscript is forthcoming in Journal of Health and Social Behavior, doi: $10.1177 / 00221465221143089$. Data used in this study are publicly available and the authors provide a replication package (Potente et al., 2022), for details see Appendix A. A blog post about this manuscript is available on UCL's Linking our Lives blog.

Previous versions of this manuscript were presented at the 2018 BSPS annual conference in Winchester, the 2018 'Rostock Retreat on Causal Inference' at the Max Planck Institute for Demographic Research, 2018 ECSR conference in Paris, the 2019 PAA annual meeting in Austin, and seminars at Nuffield College, Sciences Po, and University of Leipzig. The authors thank discussants at these occasions as well as Rachel Stuchbury and Wei Xun for invaluable help.

This study has received funding from the European Research Council (ERC) under the European Union's Horizon 2020 research and innovation program under grant agreement no. 681546 (FAMSIZEMATTERS). Patrick Präg's work was supported by the French National 
health outcomes. We interpret these findings discussing the role of universal healthcare and education for socio-economic inequality in Great Britain.

\section{INTRODUCTION}

Those with better education enjoy better health (Galama et al., 2018), and the benefits of education may also spill over to one's peers' health, such as spouses (Huijts et al., 2010) and siblings (Kravdal, 2008). Recently, intergenerational health benefits of education have received increasing attention, as bettereducated parents have healthier children (Vollmer et al., 2017) and parents to better-educated children live longer and healthier (Elo et al., 2018; Wolfe et al., 2018a,b). However, the spillovers from children to parents are understudied (De Neve and Kawachi, 2017), especially in terms of the causal relationship (Hu and Bobak, 2018). In this study we ask two questions: Are adult children's educational attainment and parental health and mortality associated in Great Britain? Does an increase in compulsory education produce benefits for population health through spillover effects from adult children to their parents?

Life course theory has long emphasized the importance of linked lives, the fact that life courses of significant others are interlocked (Elder et al., 2003). In line with this reasoning, children's life courses - including their educational attainment - can be expected to have implications for their parents' lives. We connect this theoretical perspective with 'fundamental cause' theory (Clouston and Link, 2021), which stresses the role of individuals leveraging resources to gain health advantages in the emergence of health inequalities. Based on this, our study examines how far parents are able to utilize the resources of significant others - namely the education of their children - to improve their own health.

Children's education is correlated with a number of different parental health outcomes: parents of better-educated children are less depressed (Lee et al., 2017; Sabater and Graham, 2016b; Wang et al., 2022; Wu and Penning, 2019; Yahirun et al., 2020a), have better cognitive functioning Ma et al. (2021); Yahirun et al. (2020b), suffer less from functional limitations (Yahirun et al.,

Research Agency (ANR), 'Investissements d'Avenir' [LabEx Ecodec/ANR-11-LABX-0047].

The permission of the Office for National Statistics to use the Longitudinal Study is gratefully acknowledged, as is the help provided by staff of the Center for Longitudinal Study Information and User Support (CELSIUS). CELSIUS is supported by the ESRC Census of Population Program under project ES/K000365/1. The authors alone are responsible for the interpretation of the data. ONS agrees that the figures and descriptions of results may be published. This does not imply ONS's acceptance of the validity of the methods used to obtain these figures, or of any analysis of the results. This work contains statistical data from ONS which is Crown Copyright. The use of the ONS statistical data in this work does not imply the endorsement of the ONS in relation to the interpretation or analysis of the statistical data. This work uses research datasets which may not exactly reproduce National Statistics aggregates.

The permission of Paul Norman to use the 2011 Carstairs index of deprivation he created 
2017; Zimmer et al., 2002), less from inflammation (Lee, 2018), and live longer (Elo et al., 2018; Friedman and Mare, 2014; Jiang, 2019; Sabater and Graham, 2016a; Torssander, 2013, 2014; Wolfe et al., 2018a,b; Yahirun et al., 2017; Yang et al., 2016). This has become known as the 'social foreground' hypothesis (Torssander, 2013). The evidence so far suggests there might be health benefits to children's education that extend beyond their own lives, and that investing in education is an effective strategy for improving the living conditions of a wider range of people. Some of the reported health benefits are large; Friedman and Mare (2014) for instance report that having a child with college education rather than a child who has not finished high school goes along with almost two additional years of life in the US. However, unobserved heterogeneity poses serious threats to the validity of the causal link. Since life expectancy as well as the social relationship between offspring and mother/father differ by gender, we examine men and women separately in all our analyses.

Causality is the crucial issue for the analysis of educational spillover effects. The association between children's education and parental longevity might be driven by endowments of the parental family, either socio-economic or genetic, that affect both children's education and parental longevity. However, across existing studies, the approaches used to rule out confounders often have considerable limitations. While Torssander (2013) is able to include sibling fixed effects in the parental generation which control for family background factors, all other associational studies are rarely able to include comprehensive controls for parental socio-economic status (SES). Friedman and Mare (2014) for instance control for parental income, wealth, and both parents' education, but many studies have only few control variables for the socio-economic status of the older generation at their disposal, e.g. only occupation (Zimmer et al., 2016) or education (Zimmer et al., 2007). At the same time, however, the question remains to what extent these SES indicators are actually confounders and not pathway variables by which children's education exerts its positive effects, and whether accounting for them biases the findings for children's education (De Neve and Kawachi, 2017). A confounding pathway that would link offspring education to parental longevity could be a genetic one, and indeed, genetic variants predict-

is gratefully acknowledged.

About the Authors. Cecilia Potente is a postdoctoral researcher at Jacobs Center for Productive Youth Development, University of Zurich. Her research interests are the origins, development and mechanisms of socioeconomic inequalities in health and mortality. Her work has been published in Proceedings of the National Academy of Sciences, American Journal of Epidemiology, International Journal of Epidemiology, and Population Studies. Patrick Präg is an assistant professor of sociology at the Center for Research in Economics and Statistics (CREST), ENSAE, Institut Polytechnique de Paris. Patrick is interested in intergenerational transmission and health. His recent work was published in Social Forces, Demography, and European Societies. Christiaan W. S. Monden is a professor of sociology and demography at the Department of Sociology and a fellow of Nuffield College, University of Oxford. Current research interests include social inequalities in health and mortality, fertility and family size, and family formation and dissolution. His recent work has been published in Demography, 
ing both education and longevity have recently been identified (Krapohl et al., 2014; Marioni et al., 2016).

A natural experiment allows overcoming the problems of confounding, observed or unobserved. Quasi-natural experiments exploit the variation in the key explanatory variable - in this case education - which is caused by factors outside individuals' power, such as a policy change. Our study uses the 1972 educational reform in England and Wales, which increased the minimum school leaving age from 15 to 16 years, to identify the presence of a causal effect of children's education on parental health and longevity by means of a regression discontinuity design. The intuition is that we compare children born just before the date after which they have to stay a year longer in school to those children who were born just after the cut off date. The assumption is that the negligible difference in birth timing is quasi-random and that the two groups of children differ only in whether they receive the treatment (being required to stay one year longer in school) or not and do not differ in other observed or unobserved characteristics.

The one-year increase in compulsory schooling is a good opportunity to explore the causal link between adult offspring's education and health for three reasons. First, the 1972 reform has affected a large proportion of the cohort in question, around 25 per cent (Clark and Royer, 2013), which is much higher compared to reforms in other countries such as the United States, Norway, Canada, and France (Albouy and Lequien, 2009; Black et al., 2008; Lleras-Muney, 2005; Oreopoulos, 2006). Second, the 1972 education reform had important consequences for the affected cohorts. Research has demonstrated large effects on wages and labor market outcomes (Devereux and Hart, 2010; Grenet, 2013; Oreopoulos, 2006) and some health benefits (Davies et al., 2018). Although an extra year of schooling might seem a modest amount to identify educational differences, increasing the age at school-leaving for an entire cohort represents a major effort for policymakers and educational practitioners. The 1944 Educational Act raised the minimum school-leaving age from 14 to 15 years in 1947 and put provisions into place for a second one-year increment that was to follow once conditions allowed. It took another 25 years until this happened, emphasizing the size of the undertaking that such a one-year increment means in practice. Third, the reform restricted itself to increasing the mandatory school-leaving age without implementing other changes in the educational system, making it easier to identify an effect of the reform.

Educational spillover effects have important policy implications. Improving the education of younger generations could prove to be a useful policy instrument in contexts where older populations are growing without precedence (Lutz et al., 2008), since it might serve as a public health intervention that affects not

Journal of Marriage and Family, and the European Journal of Population. 
just younger, but also older generations. Policies creating such intergenerational spillovers would also alleviate concerns about generational fairness of policy measures, in the sense that other interventions for the benefit of one generation come at the expense of another generation (Friedman and Mare, 2014). If education is a family resource that provides benefits across generational boundaries, investing in education is not a zero-sum game from a generational perspective, and a focus on the individual returns to education would underestimate the societal returns overall.

We contribute to the study of 'social foreground' in four ways. Our first contribution is to document the association between adult children's education and parental mortality in Great Britain, a context with limited public welfare provision yet a universal health care system, for the first time. We use highquality birth cohort data to document the association. Our second contribution is to examine the causal nature of the association between children's education and parental health with linked census data from England and Wales, whose large sample size allows for precise estimates. Third, we employ a regression discontinuity approach to identify the causal effect of children's education on parental mortality and health. Regression discontinuity approaches have an advantage over the instrumental variable approaches used in the existing literature, as the regression discontinuity approach allows to better discern the causal impact of the reform from a secular time trend in the data (Galama et al., 2018). Our fourth contribution is to extend our analysis beyond mortality and include self-reported health and long-standing illness as outcomes. Some mixed results found in the literature so far could be because of the wide range of outcomes being analyzed separately. By reporting results for a large number of different outcomes we aim to obtain a comprehensive picture of the causal effect of offspring's education on parental health.

Our study proceeds as follows. In the next section, we review the existing literature and identify mechanisms linking adult children's education and parental health. In a first empirical analysis, we use high-quality birth cohort data of individuals born all in one week of 1958 (Power and Elliott, 2006) to describe the association between adult children's education and parental longevity. This part of the analysis is to show that there is a clear relationship between changes in children's schooling and parental mortality in those cohorts. In the second empirical analysis, we exploit an educational reform affecting the birth cohorts from 1957 onwards and linked census data (Shelton et al., 2019) to assess whether the association between adult children's education and parental health can be considered causal. These two analyses exploit individual strengths of the two datasets and complement each other. The 1958 cohort study can be used to show the association between educational attainment and parental life expectancy, yet it does not allow ruling out crucial confounding factors using a 
quasi-experimental design. The census data allow us to use a quasi-experimental design as children vary in their birth dates around the time of an educational reform, but does not provide information on children's educational attainment necessary to establish association ${ }^{1}$. We conclude by discussing implications for universal health care and the role of education in socio-economic inequality in Great Britain.

\section{BACKGROUND}

\section{What We Know so Far}

Only few studies use exogenous variation to identify a causal effect of adult children's education on parental health (De Neve and Fink, 2018; Ludwig et al., 2021; Lundborg and Majlesi, 2018; Ma, 2019; Ma et al., 2021), relying on schooling reforms to instrument the parental health effects of an increase in children's education. Most studies are based in low- and middle-income countries (De Neve and Fink, 2018; Ludwig et al., 2021; Ma, 2019; Ma et al., 2021), showing e.g. a thirty per cent increase (1.1 years) in children's education reduced parental mortality in Tanzania by 3.7 percentage points for mothers and 0.8 percentage points for fathers (De Neve and Fink, 2018). The only study in a resourcerich setting, Sweden, does not find any overall effect (Lundborg and Majlesi, 2018). Only daughter's education has positive effects for fathers, particularly low-educated fathers, and almost a third of the increase in the likelihood to live to age 80 between 1943 and 1955 is due to an increase in daughters' schooling. However, the compulsory schooling reforms in Sweden did not only increase the number of years of schooling, but brought about other changes in the educational system, introducing a new curriculum as well as tracking, raising the question as to what exactly of the reform caused the improvement in fathers' health. Moreover, the few studies that used admission lotteries for healthcare professionals in Sweden and the Netherlands show mixed evidence for children's effects on parental health (Artmann et al., 2022; Chen et al., 2022).

\section{Theoretical Mechanisms}

There are various hypotheses on how adult children's education could be linked to parental health. Firstly, better-educated children can induce better health behaviors in their parents, which lead to greater longevity. This would be consistent with the association found by Friedman and Mare (2014). They show

\footnotetext{
${ }^{1}$ The census and cohort datasets use parent-centric and child-centric focal points respectively. While most studies connecting adult children's education and parental health have been based on parent-centric data, both focal points are equivalent for the analyses conducted here.
} 
that the association between children's education and parental longevity is particularly strong when it comes to lung cancer and chronic respiratory diseases, two causes of death linked to smoking. However, Ma (2019) does not find any causal effect of offspring's education on parents smoking and drinking intensity in China. Risky health behaviors such as alcohol consumption and smoking have long been highly prevalent in Great Britain across the 20th century and only decreased in recent years. Prevalence of binge drinking and obesity are still above the European average (OECD and European Observatory on Health Systems and Policies, 2017). Compared to the United States, Great Britain has similar smoking patterns, but lower obesity and greater heavy drinking prevalence (Banks et al., 2006). In general, old-age health for US residents appears worse than for British people across the whole socio-economic distribution (Banks et al., 2006, 2010).

Secondly, better-educated children are able to generate higher earnings (Oreopoulos, 2006; Devereux and Hart, 2010; Grenet, 2013), which would allow them to financially support their parents. For instance, De Neve and Fink (2018) interpret their finding that male education is more beneficial for parental, particularly maternal, health in Tanzania, as being due to greater labor market returns to education for this group. Yahirun et al. (2017) and Ma (2019) also find that transfer payments from children to parents are serving as a pathway affecting parental health. These financial and material pathways are likely more relevant in poorer countries, where access to health care and, more importantly, healthy living conditions are contingent on financial resources. Further, intergenerational flows of material resources in Europe mostly go from the older generation to the younger generation (Albertini et al., 2007; Attias-Donfut et al., 2005), thus it is questionable how salient this financial support pathway in Great Britain would be. However, wealthier children could buy and help buy private insurance for their parents.

Thirdly, better education opens avenues into occupational fields that have direct health benefits to parents, namely working in health care (Elo et al., 2018). This advantage can go indirectly via better information about health care as well as directly, namely via preferential access and treatment. However, for Britain, with its universal and highly centralized health care system, it is unlikely that direct effects like preferential access are operating. However, the British health care system is very complex and particularly low-educated parents could benefit from having children who know how to navigate it and to improve the doctor-patient relationship (Präg et al., 2017). Doctors are highly educated and in authoritative positions; children with more education may be more able and more comfortable to communicate with doctors and to negotiate on behalf of their parents. Also, the fundamental causes perspective on health inequalities (Phelan et al., 2010) would argue that better-educated children are better able 
to support their parents in making use of resources that reduce preventable mortality.

Fourthly, a stress pathway was recently proposed (Tosi and Albertini, 2019; Barr et al., 2018). Barr et al. (2018) showed how problems in the transition to adulthood for black adolescents (e.g. unemployment, romantic breakups, or arrests) heighten their mothers' cumulative biological risk for chronic diseases. Thus, children leaving school early might be a stressful life event that has a toll on parents' health. Moreover, successful offspring allows parents to invest fewer resources in financial and instrumental support to children. This implies that parental resources can be used to benefit the parents' own health and material circumstances.

Fifthly, shared genetic endowments might constitute a non-causal, confounding pathway linking adult children's education to parental health. This genetic confounding occurs when the genotype - partially shared between parents and children - is associated with both children's educational attainment and parental health (Krapohl et al., 2014). Marioni et al. (2016) showed that genetic variants associated with education are also linked to longevity. For example, parents of children with a strong genetic disposition for educational attainment lived half a year longer than parents of children with a weak disposition. Moreover, other sources of genetic confounding are also possible. Genetic endowments could drive selection into and exposure to individual and parental environment (Pingault et al., 2018; Kong et al., 2018). For instance, genes related to education might steer individuals into environments where health-promoting attitudes and behaviors are prevalent and which in turn might enhance individuals' and parental health. The presence of a gene-environment correlation might suggest that social environment could be structured by genotype.

The effect of children's education on their parents may differ by parental characteristics. Lower-SES parents may benefit more from having better-educated children because they have fewer resources. In their study on the Swedish population, Lundborg and Majlesi (2018) documented stronger effects of offspring's education for lower-educated fathers. However, this is not generally the case. In their analysis of older Chinese, Yang et al. (2016) did not find any differences in having higher-educated children among the different educational groups of parents, while in an analysis of eleven European countries, Sabater and Graham (2016a) find mixed associational results depending on the gender of the parent and child.

\section{Great Britain as a Research Setting}

Great Britain is a relevant setting for the study of educational spillover onto parental health. So far, evidence of educational spillovers from children to parents' health exist for resource-poor settings in Africa (De Neve and Fink, 2018; 
De Neve and Harling, 2017), for countries where family cohesion is high and intergenerational coresidence is common (Lee et al., 2017; Lee, 2018; Yahirun et al., 2016, 2017; Yang et al., 2016; Zimmer et al., 2002, 2007; Stone et al., 2014), for countries with an extensive welfare state (Elo et al., 2018; Lundborg and Majlesi, 2018; Torssander, 2013, 2014), and for the US (Friedman and Mare, 2014; Wolfe et al., 2018a,b), where filial obligations are low. Britain is unique in this context, as it combines a fairly limited welfare state that is in some ways comparable to the American one, with universal health care, namely the National Health Service, which enjoys strong public support. Yet, the British case leaves room for beneficial effects of adult children's actions: There is not a generous universal state pension that would support parents in old age (Blake, 2003). Further, behavioral health risks are more pronounced in Britain than in other European countries, with higher levels of alcohol consumption and more dangerous consumption patterns (binge drinking), more ex-smokers than in other countries, and a higher prevalence of overweight (Huijts et al., 2017; Präg et al., 2010).

While parental co-residence is rare, more than fifty per cent of Britons live within half an hour of their parents (Chan and Ermisch, 2015), levels of contact can be considered high when compared to other European countries (Tomassini et al., 2004), and more than half of children provide care to their parents by age fifty (Evandrou et al., 2018). However, the English population is found to be healthier than the US population when looking at biomarkers and self-reported conditions (Banks et al., 2006; Präg and Subramanian, 2017; Präg et al., 2022).

\section{EMPIRICAL ANALYSIS 1: COHORT STUDY}

\section{Data: 1958 National Child and Development Study}

The 1958 National Child Development Study (NCDS, Power and Elliott, 2006) is a longitudinal cohort study following the lives of all 18,558 people born in England, Scotland, and Wales in the same week in 1958 from birth until now. Follow-up has been good over time, 84 per cent of cohort members still participated at the age of 16 , with a gradual decline in participation throughout adulthood - at age 55, 8,958 respondents participated in the study, yet in midadulthood respondents were still broadly representative of the surviving cohort (Atherton et al., 2008). Next to collecting rich information about cohort members, the cohort study also asks respondents about the lives of their parents. We reconstruct parental longevity up to the most recent wave in 2013-4, when cohort members are 55 years old. ${ }^{2}$

\footnotetext{
${ }^{2}$ The 2004 wave of the NCDS did not collect information about the exact timing of parental death. For parents who deceased between the 2000 wave and the 2004 wave $(1,209$ fathers and 879 mothers) we thus do not know the exact timing of death and hence imputed a random
} 
Covariates were measured as follows. Adult children's education is based on a detailed educational qualification history, which was converted into schoolleaving age entered as a continuous variable. This coding approach ensures similarity of our estimates with Empirical Analysis 2, which uses school-leaving age to identify the causal effect of children's education on parental health and mortality. For parents, school-leaving age of respondents' fathers and mothers were reported by the parents in the 1974 wave when respondents were age 16 . We distinguish between four groups which reflect the most common educational qualifications in the parental generation. Age 13-15 years is equivalent to no qualification (reference category), age 16-17 years indicates lower secondary education, age 18-19 years denotes upper secondary or lower tertiary education, and age 20 years and more equals a university degree. Parental social class stems from the same questionnaire and is based on parental reports of occupations, self-employment status, and supervisor status. We convert this to a seven-class version of the Erikson-Goldthorpe class schema ${ }^{3}$ with a dominance approach where we only count the highest class among the two parents (Connelly et al., 2016). We further account for the sex of the child (ref. male), whether the child was born out of wedlock (ref. in wedlock), and parental age at birth.

\section{Method: Cox Regression}

To describe the association of adult children's education and parental survival, we use the Cox regression model (Cox, 1972), a semi-parametric method which makes no assumptions about the functional form of the hazard. We estimate two models: the baseline model includes adult children's education as well as the control variables sex, out-of-wedlock birth, and parental age at birth in the equation. The second model additionally controls for parental social class as well as mothers' and fathers' school-leaving age. For both models subjects enter the risk pool when parents are 45 years old.

Table 1 reports descriptive statistics concerning the children's and parents' characteristics. Only 45 per cent of the mothers have died by $2013-4$, while 67 per cent of the fathers have died. The median age at death is 69.7 years for mothers and 69.3 years for fathers. Maternal birth years range from 1910 to 1950, while paternal birth cohorts span from 1880 to 1942. Most of the cohort

year of death for the cases in question. Robustness checks showed that this did not affect our results. Cohort members' fathers and mothers were on average born in 1927 ( $S D=6.4$ years) and $1931(S D=5.7$ years), respectively. We retain 11,710 cases for which parental survival was possible to record from the 1999/2000 wave - when parental survival was first probed - and who remain in the sample at least until the 2013-4 wave or until their parents decease.

${ }^{3}$ I) professionals, administrators and managers, higher-grade (reference category), II+IVa) professionals, administrators and managers, lower-grade, small employers, higher-grade technicians, III) routine non-manual employees, IVb+c) self-employed workers (including farmers), V) lower-grade technicians, supervisors of manual workers, VI) skilled manual workers, VII) non-skilled manual workers. 
Table 1: Descriptive statistics for NCDS participants (children)

\begin{tabular}{lcc} 
& Prop./Mean & $S D$ \\
\hline Mother's avg. age at death & 69.7 & 12.3 \\
Mother deceased & 0.45 & \\
Father's avg. age at death & 69.3 & 12 \\
Father deceased & 0.67 & \\
Female child & 0.51 & \\
Child born out of wedlock & 0.04 & \\
Mother's avg. age at birth & 27.46 & 5.73 \\
Father's avg. age at birth & 30.57 & 6.45 \\
Child's age at leaving education: & 17.11 & 2.0 \\
Father's age at leaving education: & & \\
13-15 y. & 0.58 & \\
16-17 y. & 0.30 & \\
18-19 y. & 0.07 & \\
20+ y. & 0.05 & \\
Mothers's age at leaving education: & & \\
13-15 y. & 0.47 & \\
16-17 y. & 0.42 & \\
18-19 y. & 0.07 & \\
20+ y. & 0.04 & \\
Parents' social class: & & \\
I & 0.06 & \\
II+IVa & 0.12 & \\
III & 0.18 \\
IVb+c & 0.06 \\
V & 0.07 \\
VI & 0.21 \\
VII & 0.29 \\
\hline$N \quad$ Nource: NCDS (Power and Elliott, 2006), own calculations.
\end{tabular}


members were born to married parents, only four per cent to unmarried ones.

\section{Results}

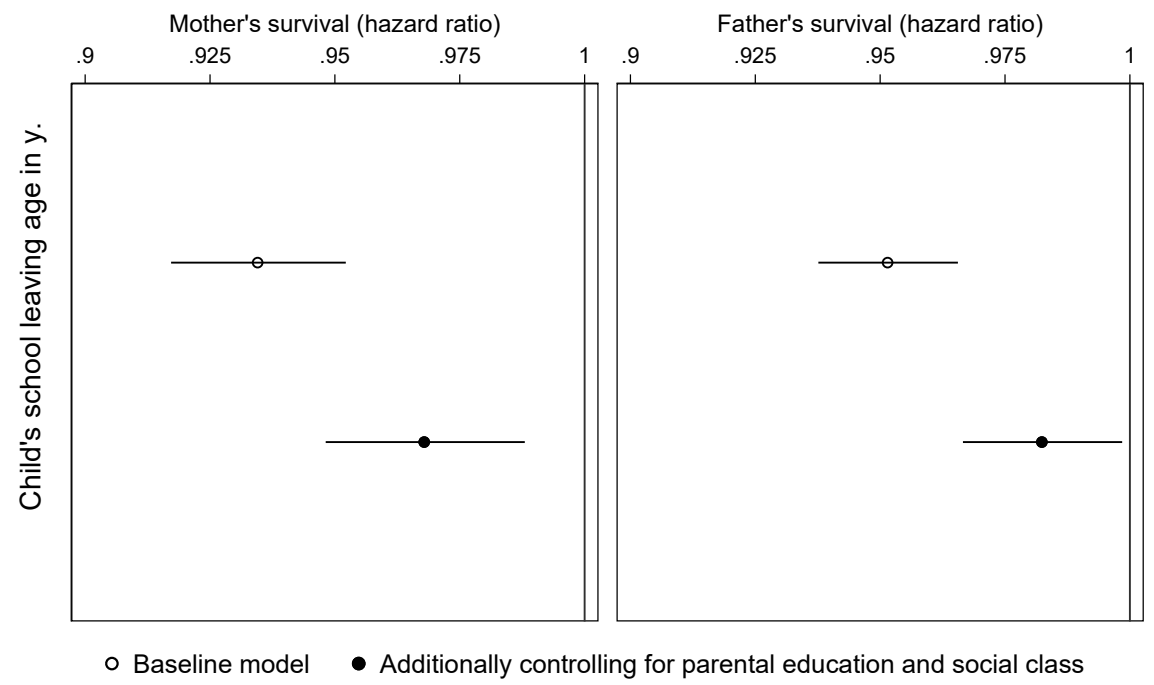

Figure 1: Better-educated children have parents who live longer (hollow dots), even when comparing parents from the same social class and with the same educational attainment (solid dots). Hazard ratios based on the models reported in Table A2.

Note: Spikes denote 95 per cent confidence intervals. Source: NCDS (Power and Elliott, 2006), own calculations.

Figure 1 presents the results from the Cox proportional hazard models and confirms the association between children's education and parental mortality. Children who have left school later have longer-living parents. In the baseline model (top row), one additional year of children's education is associated with a hazard ratio for maternal death of 0.93 (95 per cent confidence interval 0.92$0.95)$ and for paternal death of $0.95(0.94-0.97)$, corresponding to a 6 per cent and 5 per cent decrease in the expected hazard.

Once we add parental social class and parental educational attainment to the equation, the association is attenuated, yet the overall pattern holds and remains statistically significant at conventional levels. Having a child who have left education at older age is associated with an 3 per cent decrease in the expected hazards of death for mothers and 2 per cent for fathers. This is a substantially important association, as predictions of median years of life lost based on the second models suggest that parents of less-educated children (i.e. leaving school at age 16) have a two years difference compared to parents of more educated ones (i.e. leaving school at age 21). This difference is similar 
to predictions in previous studies reporting about two years difference in life expectancy (Friedman and Mare, 2014).

Finally, several robustness checks were carried out, reported in Table A4 and Table A5. First, we assessed the role of missing values by comparing the results to those obtained from using multiple imputation with chained equations (MICE, White et al., 2011). Second, we restricted the sample restricted to birth cohort members who lived in England and Wales at age 16 (excluding those living in Scotland) in order to make it comparable to the data used in Empirical Analysis 2. Third, we included an interaction of children's education with time. Fourth, we use an accelerated failure model with survival time following a Weibull distribution. In all cases, the magnitude of the coefficients changes slightly but the direction of the associations stays the same.

\section{EMPIRICAL ANALYSIS 2: LINKED CENSUS DATA}

\section{Data: The ONS Longitudinal Study}

The previous section has established the presence of associational findings while this second part of the analysis aims at determining whether there is a causal effect. We analyze the Office for National Statistics Longitudinal Study (ONSLS, Shelton et al., 2019), which combines linked census and life events data for a one-per cent sample of the population of England and Wales. The ONS-LS links records at each census since 1971 for people born on one of four selected (non-disclosed) dates in a year. Census information of the ONS-LS members is linked to life events data, including births, deaths, and cancer registrations. In 1971, women under the age of 60 who were married, widowed, or divorced were prompted to list the birth months and years of all live-born children who were born in wedlock. This birth date expressed in three-month quarters around September 1 - allows us to assess whether children were affected by the 1972 educational reform in England and Wales.

Our analytical sample includes all LS member who had children affected by the 1972 educational reform in England and Wales. It consists of 56,199 mothers who had at least one child born between 1949 and 1965. In addition, we analyze the 49,612 male ONS-LS members whose wives reported on their fertility history in the 1971 census. Table 2 describes the characteristics of the sample stratified by parental sex.

We analyze a range of both objective and subjective health outcomes. We examine mortality and premature mortality (before age 65). Respondents were followed until December 31, 2015 to assess their mortality status. Further, we distinguish between six causes of death based on the ICD classification, namely 
Table 2: Descriptive statistics for ONS-LS sample members (parents)

\begin{tabular}{lcc}
\hline & Men & Women \\
\hline Education in 1971: & & \\
\% No qualification (lower educated) & 85.4 & 90.9 \\
\% A-level (higher educated) & 8.9 & 7.9 \\
\% Higher than A-level (higher educated) & 5.6 & 1.1 \\
& & \\
\% Having children affected by reform & 51.9 & 51.1 \\
& & \\
Regional deprivation: & & \\
\% First quintile (least deprived) & 19.6 & 19.1 \\
\% Second quintile & 21.6 & 21.3 \\
\% Third quintile & 21.0 & 21.7 \\
\% Fourth quintile & 20.1 & 20.7 \\
\% Fifth quintile (most deprived) & 17.7 & 17.2 \\
Social class: & & \\
\% I/II social class & 25.3 & 23.3 \\
\% III Non-manual social class & 9.7 & 10.6 \\
\% III Manual social class & 40.2 & 35.6 \\
\% IV/V social class & 22.1 & 22.1 \\
\% Unclassified social class & 2.7 & 8.4 \\
Mean age at first birth & 29.9 & 27.2 \\
\hline$N \quad$ & 49,612 & 56,199 \\
\hline
\end{tabular}

Source: ONS-LS (Shelton et al., 2019), own calculations. 
lung cancer, accidents and self-harm, liver disease, ischaemic heart disease, mental and behavioral causes, and preventable causes in general (we define causes as preventable following the definition in Office for National Statistics, 2011). These causes of death were selected because their strong association with some health behaviors, such as smoking and excessive alcohol consumption. The aim is to test offspring's influence through parental healthy lifestyle behaviors. Further, we examine different self-reported health outcomes, namely self-reported long-standing illnesses, measured in 1991, 2001, and 2011, and self-reported poor general health, measured in 2001 and 2011. Question wordings vary slightly between census years, see Table A1 for exact phrasing. Descriptive statistics for all outcomes are shown in Table 3.

We include the following control variables in our models: parent's year of birth, dummy variables for parental occupational class, parental education (less than A-levels vs. A-levels and more), and number of children. Occupational class is indicated by the registrar-general's class scheme (Connelly et al., 2016), comprising classes I/II) ('Professional occupations' and 'Managerial and technical occupations'), III Non-manual) ('Skilled non-manual occupations'), III Manual) ('Skilled Manual occupation'), IV and V) ('Partly-skilled occupations' and 'Unskilled occupations'). Class was derived from respondent's occupation in 1971. Women married at the time of the census have been assigned the occupational class of their husband if a husband was present, otherwise their own occupational class.

The parents in our sample can of course have multiple children who may or may not be affected by the reform. Therefore, we created a data set where each case referred to one child (rather than one parent) and we conduct a child-level analysis, as each parent can have several children, of which more than one can be affected by the reform. To account for this, we weight our estimates by the inverse of the number of children a parent has, in line with Lundborg and Majlesi (2018). ${ }^{4}$

\section{Method: Regression Discontinuity Approach}

Using a regression discontinuity design, we exploit the exogenous variation in age at school completion due to compulsory schooling law changes 1972 in England and Wales. The intuition behind a regression discontinuity design is to compare cases just below and above a fixed cut-off value that determines whether cases receive the treatment. The assumption is that these cases just below and just above the threshold differ only in whether they receive the treatment, but are (on average) the same on both observed and unobserved variables. This section

\footnotetext{
${ }^{4}$ Parents with multiple children are accounted for multiple times in the analysis. To prevent the resulting over-representation of larger families, we thus weight the estimates by the inverse of the number of children. This weighting by the number of children ensures that every parent is accounted for only once.
} 
first describes the educational reform at the center of Empirical Analysis 2 and then describes our estimation approach.

\section{The 1972 educational reform in England and Wales}

Compulsory schooling laws in Britain define the maximum age at which children should start education and the minimum age at which they are allowed to leave education. Consequently, these laws determine how many years children spend in compulsory schooling. During the 20th century, two legal changes have increased the minimum ages at which children were allowed to leave school in England and Wales. First, the 1944 Educational Act, the 'Butler Act,' established an increase in school leaving age from 14 to 15 . This change was implemented from April 1, 1947 onwards. Second, the same Education Act authorized a further increase in school leaving age from 15 to 16 , which was implemented starting from September 1, 1972. This is the reform that we use for our study, as it falls in the observation period of the 1971 census and allows exploring causal effects of children's education on parental mortality in different time periods.

These schooling reforms have been exploited in previous research but none has examined the intergenerational effects that we are interested in. Clark and Royer (2013), Davies et al. (2018), and Grenet (2013) have found that the 1972 reform increased earnings for both men and women, suggesting plausible spillover effects on parents through financial resources. Davies et al. (2018) further showed that the reform significantly reduced blood pressure, diabetes, heart attack risk, body mass index, sedentary and unhealthy behaviors. However, not all studies show positive effects of the 1972 reform on health and health behaviors and knowledge (Clark and Royer, 2013; Silles, 2009; Janke et al., 2020; Johnston et al., 2015). For example, Jürges et al. (2013) have not found any effect on self-rated health and some biomarkers, such as level of fibrinogen and C-reactive protein. Similarly, Powdthavee (2010) showed that the 1972 reform did not decrease significantly the likelihood of hypertension. Despite the unclear effect of the 1972 educational reform on the health of the affected cohorts, it remains important to study the spillover effects of children's education on parental health and mortality. The mechanisms linking children's education to parental health that we have hypothesized are not necessarily dependent children's health but could also operate via behaviors and earnings which have been found to be affected by the educational reform (Clark and Royer, 2013; Davies et al., 2018; Grenet, 2013).

Figure 2 shows the increase in school-leaving age across birth cohorts in England. The 1972 reform has a clear effect in producing a discontinuous increase in years of education across birth cohorts. Furthermore, we can see that compliance with the reform is high. The reform reduced the percentage of individuals 
with only nine years of schooling by almost seventeen percentage points. Next to that, the reform also did not affect the percentage of individuals with more than 16 years of education. We rely on the Health Surveys for England (19912013) for demonstrating this discontinuity, because we only know the quarter of birth, not the actual educational attainment of the children of ONS-LS sample members.

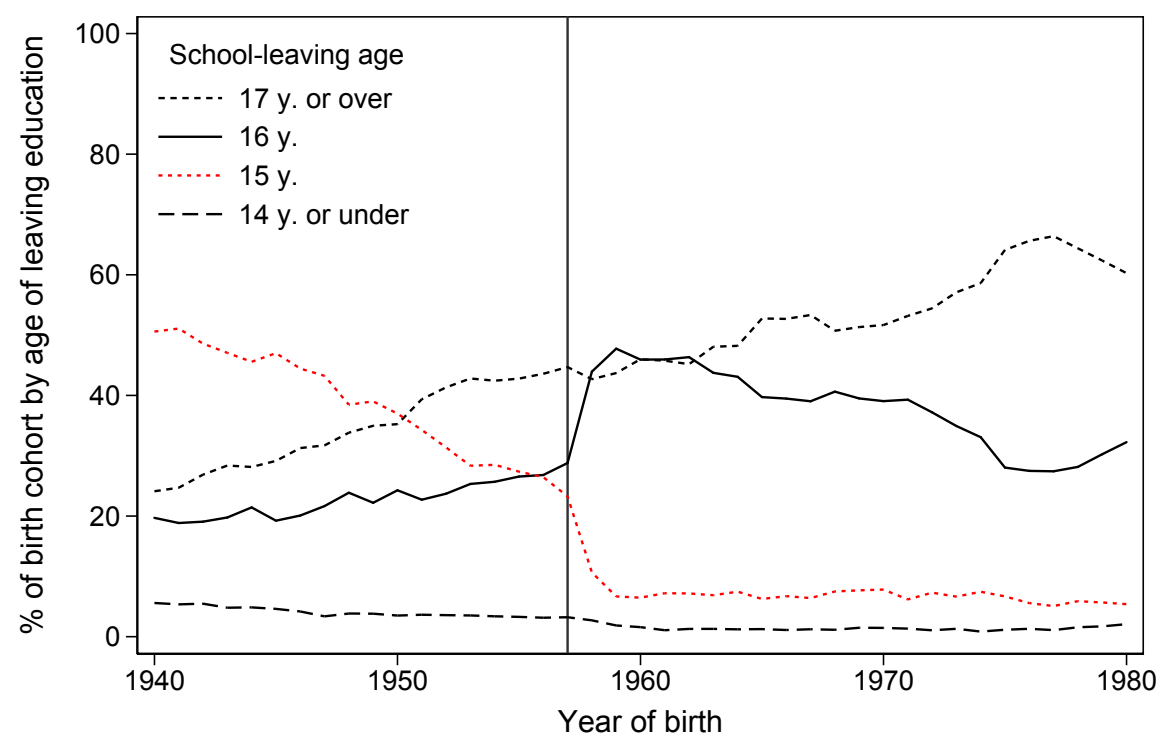

Figure 2: The 1972 educational reform greatly reduced the share of individuals leaving school at age 15 for those born after September 1, 1957. Years of fulltime education by year of birth.

Source: Health Surveys for England, 1991-2013 (Mindell et al., 2012), own calculations.

\section{Identification strategy}

Identification is achieved through a regression discontinuity (RD) approach (Imbens and Lemieux, 2008; Lee and Lemieux, 2010). In particular, RD designs have four main features: the running variable, the treatment, the cut-off, and the bandwidth. The running variable is the children's date of birth, measured in quarter of birth (due to confidentiality restrictions imposed by the data provider), that leads to the assignment of the treatment. Second, the treatment is the increase in years of compulsory education for individuals born after September 1, 1957. The cut-off represents the quarter of birth after which the treatment is assigned. Therefore, the probability of treatment assignment based on the running variable has a discontinuous change after the reform implementation. Finally, the accuracy of estimation depends on the bandwidth, 
i.e. the number of observations right before and after the reform threshold. It is crucial that the bandwidth estimation procedure is conducted in a data-driven way, such that the trade-off between bias (i.e. when the bandwidth is large, the larger is the bias) and variance (i.e. when the bandwidth is small, the larger is the variance) is minimized.

Our design is a 'fuzzy' (as opposed to 'sharp') regression discontinuity approach because the reform increases the probability to stay in education until age 16 but does not solely determine whether a student stays in school. All the analyses are carried out with the Stata package 'rdrobust' (Calonico et al., 2017). We use a data-driven bandwidth estimation procedure (using the same mean square error optimal bandwidth on both sides) and check the sensitivity of the results to different bandwidths and bandwidths' selection algorithm. Following Gelman and Imbens (2019), we chose a linear fit for the running variable and calculate robust standard errors. We add a number of control variables (listed above) to our models. We include control variables in our models because they increase the precision of the estimates by removing small residual imbalances between groups.

Using a regression discontinuity design to study the effects of a policy reform has an advantage over studies relying on instrumental variable (IV) approaches to estimate causal effects. IV methods in quasi-experimental settings can be sensitive to cohort trends in mortality. In particular, small effects of offspring's education on parental mortality due to an educational reform are more difficult to distinguish from secular changes in mortality when an IV approach is used (Galama et al., 2018). Our RD approach allows us to address such a bias.

We compare cases with children born right before and after the cut-off date. For illustration, Table 3 shows outcome variables and parental covariates for children born one year before and one year after the reform. The groups are balanced for the covariates, supporting the assumption of quasi-random assignment to the reform, but we observe some differences for the outcomes. The actual sample size in the models of the different outcomes depends on bandwidth used, as well as the number of non-missing observations for each outcome. We conducted an ex-post power analysis using the 'rdpower' command in Stata (Cattaneo et al., 2019) in order to check whether a lack of statistical power can account for our results. The power analysis concludes that we have more than enough power (larger than 0.8 , which is the customary threshold for power) to detect effect sizes half of a standard deviation of the outcome for the untreated and even smaller effect for many of the outcomes. Detailed information about the sample size for each estimation as well as the results from the power analysis are available in the supplementary materials.

The estimated treatment effects represent intention-to-treat effects (ITT), which are the causal effects of children's reform eligibility defined by the thresh- 
old rule (i.e. born after September 1, 1957) on parental health and mortality outcomes. ITT use the quasi-random assignment to the policy reform (since individuals cannot manipulate their date of birth) and thus are the average impact of the reform both for those who actually stay one additional year in compulsory education and for those who do not. How does an ITT differ from the average treatment effect, i.e. the effect of one additional year of education who actually stayed in school one year longer? The ITT does not take into account non-compliance (i.e. individuals who drop out of school before reaching the mandatory school age despite the reform), making it potentially smaller than the average treatment effect. Yet, previous studies have found very few people leaving school before compulsory age after the reform we build our analysis on (Clark and Royer, 2013; Silles, 2009). Therefore we expect that our ITT is not substantively different from the average treatment effect. Data restrictions make it impossible to estimate the causal effect on those who comply to the policy reform (i.e. only those who stay one year more in compulsory schooling) since the linked census data contain only the date of birth but not the age at school leaving or educational attainment as children's information. 
Table 3: Descriptive statistics for outcome variables and covariates for parents with any children born between one year before and one year after the reform

\begin{tabular}{|c|c|c|}
\hline & $\begin{array}{l}\text { Without children } \\
\text { affected by reform }\end{array}$ & $\begin{array}{l}\text { With children } \\
\text { affected by reform }\end{array}$ \\
\hline \multicolumn{3}{|l|}{ Outcome variables } \\
\hline$\%$ deceased until December 31, 2015 & 62.1 & 55.9 \\
\hline$\%$ deceased before age 65 until December 31, 2015 & 14.2 & 14.7 \\
\hline$\%$ died of lung cancer & 5.4 & 4.6 \\
\hline$\%$ died of accidents and self-harm & 1.0 & 1.0 \\
\hline$\%$ died of liver disease & 0.8 & 0.7 \\
\hline$\%$ died of ischaemic heart disease & 11.3 & 8.9 \\
\hline$\%$ died of mental and behavioral causes & 1.5 & 1.6 \\
\hline$\%$ died of preventable causes & 8.0 & 7.9 \\
\hline \% longstanding illness in 1991 census & 24.3 & 21.7 \\
\hline$\%$ longstanding illness in 2001 census & 43.3 & 41.4 \\
\hline$\%$ longstanding illness in 2011 census & 63.6 & 60.5 \\
\hline$\%$ poor self-rated health in 2001 census & 20.9 & 18.9 \\
\hline$\%$ poor self-rated health in 2011 census & 18.1 & 16.8 \\
\hline \multicolumn{3}{|l|}{ Parental covariates } \\
\hline$\%$ women & 52.6 & 52.5 \\
\hline Average number of children & 2.7 & 2.6 \\
\hline Average parental year of birth & 1928 & 1930 \\
\hline$\%$ higher educated & 12.3 & 12.7 \\
\hline \multicolumn{3}{|l|}{ Social class: } \\
\hline$\% \mathrm{I} / \mathrm{II}$ & 25.3 & 25.6 \\
\hline$\%$ III Non-manual & 9.9 & 9.9 \\
\hline \% III Manual & 38.0 & 37.6 \\
\hline$\% \mathrm{IV} / \mathrm{V}$ & 20.9 & 21.7 \\
\hline$\%$ Unclassified & 5.7 & 5.5 \\
\hline$N$ & 6,089 & 6,057 \\
\hline
\end{tabular}

Source: ONS-LS (Shelton et al., 2019), own calculations.

\section{Results}

Figure 3 shows the proportion of parents who have died before 2016 by children's quarter of birth. We observe a discontinuity for parents' mortality: the proportion of deceased parents drops sharply for those whose children were affected by the reform. The discontinuity is more pronounced for fathers than for mothers.

Figure 4 presents the results from regression discontinuity analyses for all thirteen outcomes, stratified by parental sex. A pattern emerges: coefficients do not always point in the expected direction and usually do not reach conven- 

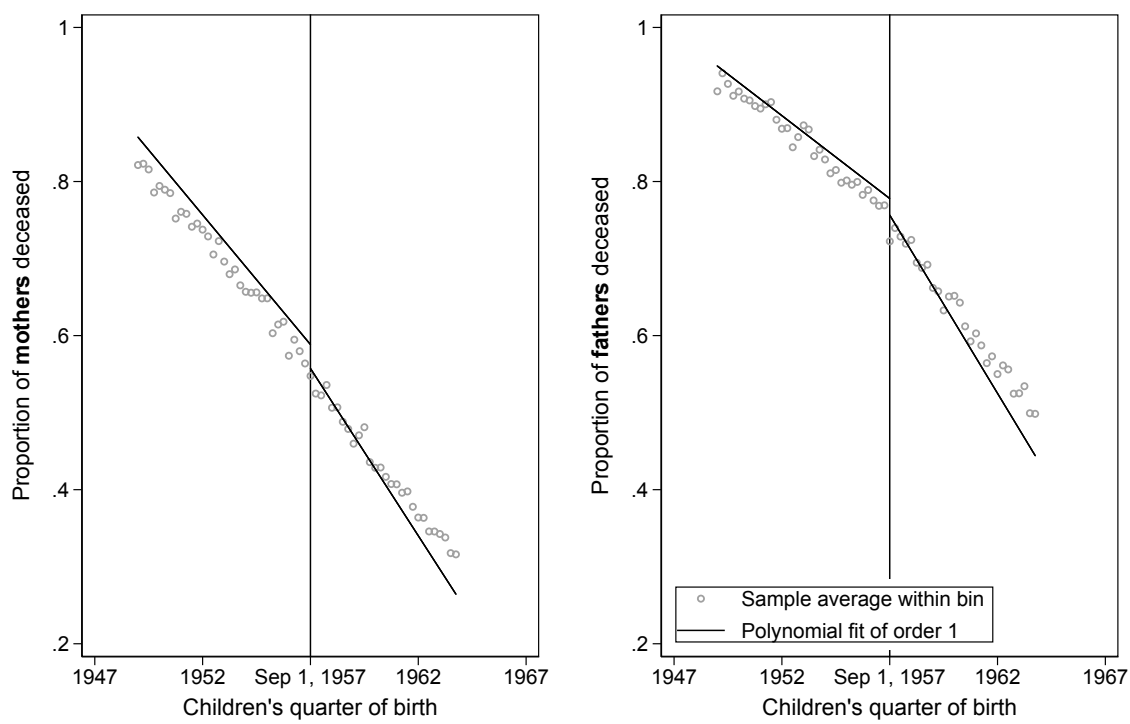

Figure 3: The proportion of deceased parents decreased sharply for those whose children were affected by the reform

Source: ONS-LS (Shelton et al., 2019), own calculations.

tional levels of statistical significance. Mothers with children affected by the reform experience a small reduction in mortality. Having a child affected by the reform reduces the probability of dying by 1.4 per cent, yet this estimate does not reach conventional levels of statistical significance (95\% confidence interval: $-4.0 \%-1.2 \%)$. For fathers, the coefficient points in the same direction $(-0.7 \%$, $95 \%$ CI: $-2.9 \%-1.5 \%$ ), but similarly it is not significant at conventional levels. Two estimates that do reach conventional levels of statistical significance are for women the risk of dying of ischaemic heart disease $(-1.7 \%,-3 \%--0.2 \%)$ and for men the risk of dying of liver disease $(-0.5 \%,-0.9 \%-0.04 \%)$. However, after correction for multiple comparisons with the Benjamini-Hochberg procedure for the six causes of death considered here, neither of these results is significant.

We further stratify the models by the socioeconomic position of the parents. Results show that there is no systematic difference by parental socioeconomic position in the effect of children's education on parents' outcomes. Results can be found in Figure A3 in the Supplementary Materials.

We conducted several robustness checks. First, we check that the results in Figure 4 are robust to multiple comparison correction using the BenjaminiHochberg procedure for multiple tests in the causes of death considering them as independent outcomes. Results show that none of the coefficients remain 


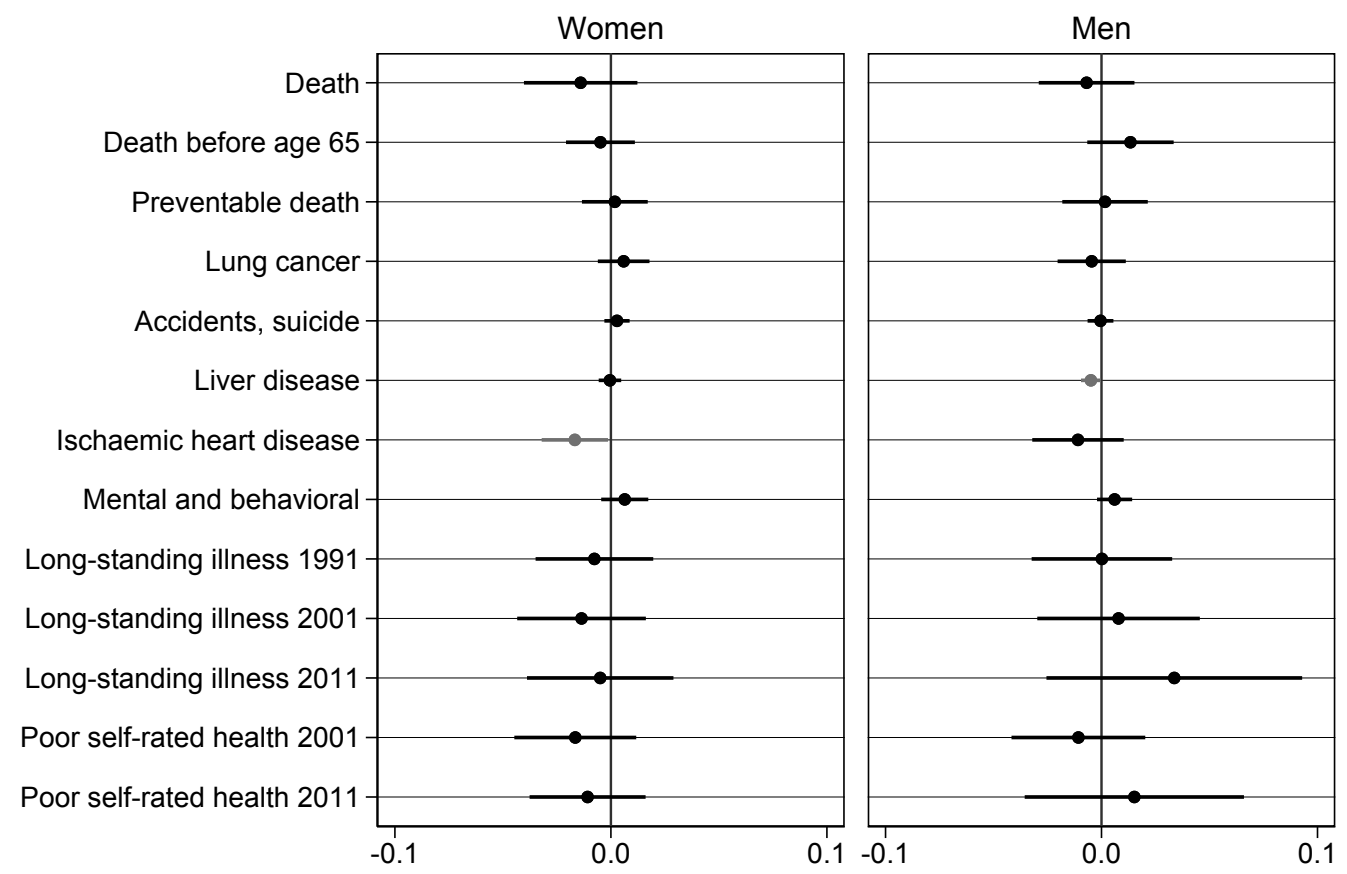

Figure 4: RD estimates of educational reform stratified by parental sex

Notes: Error bars denote 95\% confidence interval based on robust standard errors. Controls comprise parental education, number of children, occupational class, and year of birth. Estimates shown in Table A3. Source: ONS-LS (Shelton et al., 2019), own calculations. 
significant after this adjustment. Second, in Figure A4 we stratified the models by parental education and by area deprivation as two additional measures of parental class. While a number of estimates are statistically significant (at the $5 \%$-level), they are specific to single SES indicators, which does not support a notion that lower-SES parents benefit more from better-educated children. Third, in Table A7 we stratified models by the number of children that parents had. Effects might be especially pronounced among parents whose only child was affected by the reform rather than among parents with more children, some of whom will not be affected by the reform. This robustness check did not reveal any significant effects, which is in line with our overall findings. Finally, in Table A10 we investigate the effects of choosing different bandwidths around the threshold date. The results remain the same when different bandwidths are selected, demonstrating low sensitivity to the bandwidth chosen.

\section{CONCLUSION}

This study explored the intergenerational consequences of education for population health in Great Britain. First, we establish that there is an association between adult offspring's education and parental mortality in Great Britain, which exists even when comparing only parents with the same occupational class background and the same educational attainment. Specifically, having a better-educated child increases median parental longevity by two years. Second, using an educational reform as a natural experiment, we analyze linked census data from England and Wales to show that the increase of children's schoolleaving age from 15 to 16 had no significant causal effect on parental health, overall mortality or specific causes of death. An investigation into heterogeneous treatment effects by parental socio-economic status shows that health benefits do not accrue particularly for parents from disadvantaged backgrounds, regardless of indicator of disadvantage we use.

In the first analysis we find a significant association between adult children's education and parental longevity. From our second analysis, we conclude that this association does not result from a direct causal effect of education on parental health using a local experiment. We propose the absence of a causal effect in our study might be explained by three aspects in which the British context is unique: universal health care coverage, the relevance of education for determining socio-economic position, and the location of the change in education brought about by the 1972 schooling reform. First, we have to take into account the potentially equalizing effect of the National Health Service (NHS) in Great Britain. The NHS provides universal and comprehensive access to health care free at the point of use and covering all health care needs over the entire life course. This single-payer health care system potentially removes financial 
barriers to accessing health care, making parents rely less on their children's economic resources for support.

Second, a possible explanation could be that in Great Britain occupational class - rather than education - is particularly salient for life chances, especially compared to countries such as the US, where education is a more important driver of life chances. Parental occupational class of origin is a major predictor of children's pay, even in professional and managerial occupations in the United Kingdom (Laurison and Friedman, 2016). Previous studies have shown the effect of the reform has increased the probability of working in non-manual occupations, in particular in the sectors of public administration, health, and education (Lepinteur and Nieto, 2021).

Third, the educational reform increased school-leaving age from 15 to 16 years, which, although an important increase in overall educational level of the population and with documented effects on income, might not have been salient enough for an overall health effect. However, it is the least advantaged young people who could have benefited the most from the additional year in compulsory schooling. Therefore, we expect that the policy reform would have affected the intergenerational life chances of the most disadvantaged families. Moreover, there might be causal effects of offspring's education at other points of the educational distribution, for example receiving college education compared to having only secondary education. Given our focus on a quasi-natural experiment that raised the mandatory school leaving age from 15 to 16 , we could not establish effects at other points in the educational distribution. Madia et al. (2022) expands our analyses to include a reform that increased the school-leaving age from 14 to 15 years of age. Reforms in other settings that affected tertiary education would be a tool to identify such effects.

We find no evidence for low-SES parents benefiting more strongly from their children's education. This is a particularly striking finding, as we would expect to find the strongest effect for low-SES parents. The only other causal study in a resource-rich setting, examining an educational reform in Sweden (Lundborg and Majlesi, 2018), found effects for the health of lower-educated parents only, not for higher-educated parents. However, these effects only materialized for specific gender combinations, namely for fathers of daughters, which we cannot investigate with the data at hand.

Our study is not free from limitations. First, while it would be interesting to study additive effects of children education on parental health, due to the very reduced number of multiple births in the dataset this analysis could not been carried out. Second, the absence of a causal effect has to be understood locally and therefore, we cannot exclude the presence of an effect at other points in the educational distribution. Third, the data in hand did not allow us to make direct tests of potential causal mechanisms linking adult children's education 
and parental longevity, such as learning of improved health behaviors, increased material resources and reduced stress. Finally, parents in the first NCDS analysis are known to have some contact with their children (who respond to the survey at age 45), the second study uses ONS-LS census-linked data which does not assure any direct contact with the children after the birth of child.

The fundamental causes perspective on health inequalities (Clouston and Link, 2021) posits that socio-economic inequalities arise when it is possible for more socio-economically advantaged individuals to obtain health benefits by leveraging resources available to them. In the context of linked lives, the theory expects that the more preventable a disease is, the more responsive it would be to an increase in offspring's education. However, we compared different causes of death that should be particularly prone to improve with children's education without finding any effect. This absence of consistent evidence for other causes of death or health indicators limits our ability to draw definitive conclusions on this mechanism.

Therefore, improving the education of younger generations might be a useful policy instrument with intergenerational benefits in the context of aging populations. Such an educational expansion might not just improve the human capital of younger generations, but also have positive spillover effects that improve the health of older generations. Our study is the first to comprehensively test the causal effect of adult children's education on a comprehensive set of health and mortality outcomes in a high-income country with an aging population. Our results suggest the presence of a significant association between children's education and parental health. However, neither parental health nor longevity is affected by children's exogenous increase in education, casting doubts on the intergenerational benefits of human capital investments.

\section{References}

Albertini, Marco, Martin Kohli, and Claudia Vogel, 2007. 'Intergenerational Transfers of Time and Money in European Families. Common Patterns, Different Regimes?' Journal of European Social Policy 17(4): 319-334. doi: 10.1177/0958928707081068.

Albouy, Valerie and Laurent Lequien, 2009. 'Does Compulsory Education Lower Mortality?' Journal of Health Economics 28(1): 155-168. doi: 10.1016/j.jhealeco.2008.09.003.

Artmann, Elisabeth, Hessel Oosterbeek, and Bas van der Klaauw, 2022. 'Do Doctors Improve the Health Care of Their Parents? Evidence from Admission Lotteries.' American Economic Journal: Applied Economics 14(3): 164-84. doi: 10.1257/app.20190629. 
Atherton, Kate, Elizabeth Fuller, Peter Shepherd, David P. Strachan, and Chris Power, 2008. 'Loss and Representativeness in a Biomedical Survey at Age 45 Years. 1958 British Birth Cohort.' Journal of Epidemiology and Community Health 62(3): 216-223. doi: 10.1136/jech.2006.058966.

Attias-Donfut, Claudine, Jim Ogg, and François-Charles Wolff, 2005. 'European Patterns of Intergenerational Financial and Time Transfers.' European Journal of Aging 2(3): 161-173. doi: 10.1007/s10433-005-0008-7.

Banks, James, Michael Marmot, Zoe Oldfield, and James P. Smith, 2006. 'Disease and Disadvantage in the United States and in England.' JAMA 295(17): 2037-2045. doi: 10.1001/jama.295.17.2037.

Banks, James, Alastair Muriel, and James P. Smith, 2010. 'Disease Prevalence, Disease Incidence, and Mortality in the United States and in England.' Demography 47(Supplement): S211-S231. doi: 10.1353/dem.2010.0008.

Barr, Ashley B., Leslie Gordon Simons, Ronald L. Simons, Steven R. H. Beach, and Robert A. Philibert, 2018. 'Sharing the Burden of the Transition to Adulthood. African American Young Adults' Transition Challenges and Their Mothers' Health Risk.' American Sociological Review 83(1): 143-172. doi: 10.1177/0003122417751442.

Black, Sandra E., Paul J. Devereux, and Kjell G. Salvanes, 2008. 'Staying in the Classroom and Out of the Maternity Ward? The Effect of Compulsory Schooling Laws on Teenage Births.' Economic Journal 118(530): 1025-1054. doi: 10.1111/j.1468-0297.2008.02159.x.

Blake, David, 2003. 'The UK Pension System. Key Issues.' Pensions. An International Journal 8(4): 330-375. doi: 10.1057/palgrave.pm.5940242.

Boyle, Paul, Paul Norman, and Philip Rees, 2004. 'Changing Places. Do Changes in the Relative Deprivation of Areas Influence Limiting Long-Term Illness and Mortality among Non-Migrant People Living in Non-Deprived Households?' Social Science and Medicine 58(12): 2459-2471. doi: 10.1016/j.socscimed.2003.09.011.

Calonico, Sebastian, Matias D. Cattaneo, Max H. Farrell, and Rocío Titiunik, 2017. 'rdrobust. Software for Regression-Discontinuity Designs.' Stata Journal 17(2): 372-404. doi: 10.1177/1536867X1701700208.

Calonico, Sebastian, Matias D. Cattaneo, and Rocio Titiunik, 2014. 'Robust Nonparametric Confidence Intervals for Regression-Discontinuity Designs.' Econometrica 82(6): 2295-2326. doi: https://doi.org/10.3982/ECTA11757. 
Cattaneo, Matias D., Rocío Titiunik, and Gonzalo Vazquez-Bare, 2019. 'Power Calculations for Regression Discontinuity Designs.' Stata Journal 19(1): 210245. doi: $10.1177 / 1536867 \times 19830919$.

Chan, Tak Wing and John Ermisch, 2015. 'Proximity of Couples to Parents. Influences of Gender, Labor Market, and Family.' Demography 52(2): 379 399. doi: 10.1007/s13524-015-0379-0.

Chen, Yiqun, Petra Persson, and Maria Polyakova, 2022. 'The Roots of Health Inequality and the Value of Intrafamily Expertise.' American Economic Journal: Applied Economics 14(3): 185-223. doi: 10.1257/app.20200405.

Clark, Damon and Heather Royer, 2013. 'The Effect of Education on Adult Mortality and Health. Evidence from Britain.' American Economic Review 103(6): 2087-2120. doi: 10.1257/aer.103.6.2087.

Clouston, Sean A. P. and Bruce G. Link, 2021. 'A Retrospective on Fundamental Cause Theory. State of the Literature and Goals for the Future.' Annual Review of Sociology 47: 131-156. doi: 10.1146/annurev-soc-090320-094912.

Connelly, Roxanne, Vernon Gayle, and Paul S. Lambert, 2016. 'A Review of Occupation-Based Social Classifications for Social Survey Research.' Methodological Innovations 9: 1-14. doi: 10.1177/2059799116638003.

Cox, David, 1972. 'Regression Models and Life Tables.' Journal of the Royal Statistical Society B 34(2): 187-220. doi: 10.1111/j.2517-6161.1972.tb00899.x.

Davies, Neil M., Matt Dickson, George Davey Smith, Gerard J. van den Berg, and Frank Windmeijer, 2018. 'The Causal Effects of Education on Health Outcomes in the UK Biobank.' Nature Human Behavior 2: 117-125. doi: 10.1038/s41562-017-0279-y.

De Neve, Jan-Walter and Günther Fink, 2018. 'Children's Education and Parental Old Age Survival. Quasi-Experimental Evidence on the Intergenerational Effects of Human Capital Investment.' Journal of Health Economics 58: 76-89. doi: 10.1016/j.jhealeco.2018.01.008.

De Neve, Jan-Walter and Guy Harling, 2017. 'Offspring Schooling Associated with Increased Parental Survival in Rural KwaZulu-Natal, South Africa.' Social Science and Medicine 176: 149-157. doi: 10.1016/j.socscimed.2017.01.015.

De Neve, Jan-Walter and Ichiro Kawachi, 2017. 'Spillovers between Siblings and from Offspring to Parents Are Understudied. A Review and Future Directions for Research.' Social Science and Medicine 183: 56-61. doi: 10.1016/j.socscimed.2017.04.010. 
Devereux, Paul and Robert A. Hart, 2010. 'Forced to be Rich? Returns to Compulsory Schooling in Britain.' Economic Journal 120(549): 1345-1364. doi: 10.1111/j.1468-0297.2010.02365.x.

Elder, Jr., Glenn H., Monica Kirkpatrick Johnson, and Robert Crosnoe, 2003. 'The Emergence and Development of Life Course Theory.' In Mortimer, Jeylan T. and Michael Shanahan, eds., Handbook of the Life Course, pp. 3-19. New York: Kluwer. doi: 10.1007/978-0-306-48247-2_1.

Elo, Irma T., Pekka Martikainen, and Mikko Aaltonen, 2018. 'Children's Educational Attainment, Occupation, and Income and Their Parents' Mortality.' Population Studies 72(1): 53-73. doi: 10.1080/00324728.2017.1367413.

Evandrou, Maria, Jane Falkingham, Madelin Gomez-Leon, and Athina Vlachantoni, 2018. 'Intergenerational Flows of Support Between Parents and Adult Children in Britain.' Aging and Society 38(2): 321-351. doi: 10.1017/S0144686X16001057.

Friedman, Esther M. and Robert D. Mare, 2014. 'The Schooling of Offspring and the Survival of Parents.' Demography 51(4): 1271-1293. doi: 10.1007/s13524014-0303-z.

Galama, Titus J., Adriana Lleras-Muney, and Hans van Kippersluis, 2018. 'The Effect of Education on Health and Mortality. A Review of Experimental and Quasi-Experimental Evidence.' In Hamilton, Jonathan H., ed., Oxford Research Encyclopedia of Economics and Finance, pp. 1-93. Oxford: Oxford University Press. doi: 10.1093/acrefore/9780190625979.013.7.

Gelman, Andrew and Guido Imbens, 2019. 'Why High-Order Polynomials Should Not Be Used in Regression Discontinuity Designs.' Journal of Business and Economic Statistics 37(3): 447-456. doi: 10.1080/07350015.2017.1366909.

Grenet, Julien, 2013. 'Is Extending Compulsory Schooling Alone Enough to Raise Earnings? Evidence from French and British Compulsory Schooling Laws.' Scandinavian Journal of Economics 115(1): 176-210. doi: 10.1111/j.1467-9442.2012.01739.x.

$\mathrm{Hu}$, Yaoyue and Martin Bobak, 2018. 'Upward Intergenerational Transmission of Health Inequality.' Journal of Epidemiology and Community Health 72(11): 971-972. doi: 10.1136/jech-2018-211282.

Huijts, Tim, Christiaan W. S. Monden, and Gerbert Kraaykamp, 2010. 'Education, Educational Heterogamy, and Self-Assessed Health in Europe. A Multilevel Study of Spousal Effects in 29 European Countries.' European Sociological Review 26(3): 261-276. doi: 10.1093/esr/jcp019. 
Huijts, Tim, Per Stornes, Terje A. Eikemo, Clare Bambra, and The HiNews Consortium, 2017. 'The Social and Behavioral Determinants of Health in Europe.' European Journal of Public Health 27(Supplement 1): 55-62. doi: 10.1093/eurpub/ckw231.

Imbens, Guido W. and Thomas Lemieux, 2008. 'Regression Discontinuity Designs. A Guide to Practice.' Journal of Econometrics 142(2): 615-635. doi: 10.1016/j.jeconom.2007.05.001.

Janke, Katharina, David W. Johnston, Carol Propper, and Michael A. Shields, 2020. 'The Causal Effect of Education on Chronic Health Conditions in the UK.' Journal of Health Economics 70: 102252. doi: 10.1016/j.jhealeco.2019.102252.

Jiang, Nan, 2019. 'Adult Children's Education and Later-Life Health of Parents in China. The Intergenerational Effects of Human Capital Investment.' Social Indicators Research 145: 257-278. doi: 10.1007/s11205-019-02109-9.

Johnston, David W., Grace Lordan, Michael A. Shields, and Agne Suziedelyte, 2015. 'Education and Health Knowledge. Evidence from UK Compulsory Schooling Reform.' Social Science and Medicine 127: 92-100. doi: 10.1016/j.socscimed.2014.10.026.

Jürges, Hendrik, Eberhard Kruk, and Steffen Reinhold, 2013. 'The Effect of Compulsory Schooling on Health. Evidence from Biomarkers.' Journal of Population Economics 26(2): 645-672. doi: 10.1007/s00148-012-0409-9.

Kong, Augustine, Gudmar Thorleifsson, Michael L. Frigge, Bjarni J. Vilhjalmsson, Alexander I. Young, Thorgeir E. Thorgeirsson, Stefania Benonisdottir, Asmundur Oddsson, Bjarni V. Halldorsson, Gisli Masson, Daniel F. Gudbjartsson, Agnar Helgason, Gyda Bjornsdottir, Unnur Thorsteinsdottir, and Kari Stefansson, 2018. 'The Nature of Nurture. Effects of Parental Genotypes.' Science 359(6374): 424-428. doi: 10.1126/science.aan6877.

Krapohl, Eva, Kaili Rimfeld, Nicholas G. Shakeshaft, Maciej Trzaskowski, Andrew McMillan, Jean-Baptiste Pingault, Kathryn Asbury, Nicole Harlaar, Yulia Kovas, Philip S. Dale, and Robert Plomin, 2014. 'The High Heritability of Educational Achievement Reflects Many Genetically Influenced Traits, not just Intelligence.' Proceedings of the National Academy of Sciences 111(42): 15273-15278. doi: 10.1073/pnas.1408777111.

Kravdal, Øystein, 2008. 'A Broader Perspective on Education and Mortality. Are We Influenced by other People's Education?' Social Science and Medicine 66(3): 620-636. doi: 10.1016/j.socscimed.2007.10.009. 
Laurison, Daniel and Sam Friedman, 2016. 'The Class Pay Gap in Higher Professional and Managerial Occupations.' American Sociological Review 81(4): 668-695. doi: 10.1177/0003122416653602.

Lee, Chioun, 2018. 'Adult Children's Education and Physiological Dysregulation Among Older Parents.' Journals of Gerontology B 73(6): 1143-1154. doi: 10.1093/geronb/gbx044.

Lee, Chioun, Dana A. Glei, Noreen Goldman, and Maxine Weinstein, 2017. 'Children's Education and Parents' Trajectories of Depressive Symptoms.' Journal of Health and Social Behavior 58(1): 86-101. doi: 10.1177/0022146517690200.

Lee, David S. and Thomas Lemieux, 2010. 'Regression Discontinuity Designs in Economics.' Journal of Economic Literature 48(2): 281-355. doi: $10.1257 /$ jel.48.2.281.

Lepinteur, Anthony and Adrìan Nieto, 2021. 'All about the Money? The Gendered Effect of Education on Industrial and Occupational Sorting.' CEPREMAP Working Papers 2109: 1-53.

Lleras-Muney, Adriana, 2005. 'The Relationship between Education and Adult Mortality in the United States.' Review of Economic Studies 72: 189-221. doi: 10.1111/0034-6527.00329.

Ludwig, Jan Ole, Neil M. Davies, Jacob Bor, and Jan-Walter De Neve, 2021. 'Causal Effect of Children's Secondary Education on Parental Health Outcomes. Findings from a Natural Experiment in Botswana.' BMJ Open 11(e043247): 1-11. doi: 10.1136/bmjopen-2020-043247.

Lundborg, Petter and Kaveh Majlesi, 2018. 'Intergenerational Transmission of Human Capital. Is It a One-Way Street?' Journal of Health Economics 57: 206-220. doi: 10.1016/j.jhealeco.2017.12.001.

Lutz, Wolfgang, Warren Sanderson, and Sergei Scherbov, 2008. 'The Coming Acceleration of Global Population Aging.' Nature 451(7179): 716-719. doi: 10.1038/nature06516.

Ma, Mingming, 2019. 'Does Children's Education Matter for Parents' Health and Cognition? Evidence from China.' Journal of Health Economics 66: 222-240. doi: 10.1016/j.jhealeco.2019.06.004.

Ma, Mingming, Jenjira Yahirun, Joseph Saenz, and Connor Sheehan, 2021. 'Offspring Educational Attainment and Older Parents' Cognition in Mexico.' Demography 58(1): 75-109. doi: 10.1215/00703370-8931725. 
Madia, Joan, Patrick Präg, and Christiaan Monden, 2022. 'Does Children's Education Improve Parental Longevity? Evidence from Two Educational Reforms in England.' SocArXiv doi: 10.31235/osf.io/9n8q5.

Marioni, Riccardo E., Stuart J. Ritchie, Peter K. Joshi, Saskia P. Hagenaars, Aysu Okbay, Krista Fischer, Mark J. Adams, W. David Hill, Gail Davies, Reka Nagy, Carmen Amador, Kristi Läll, Andres Metspalu, David C. Liewald, Archie Campbell, James F. Wilson, Caroline Hayward, Tõnu Esko, David J. Porteous, Catharine R. Gale, and Ian J. Deary, 2016. 'Genetic Variants Linked to Education Predict Longevity.' Proceedings of the National Academy of Sciences 113(47): 13366-13371. doi: 10.1073/pnas.1605334113.

Mindell, Jennifer, Jane P. Biddulph, Vasant Hirani, Emanuel Stamatakis, Rachel Craig, Susan Nunn, and Nicola Shelton, 2012. 'The Health Survey for England.' International Journal of Epidemiology 41(6): 1585-1593. doi: 10.1093/ije/dyr199.

Morris, Russell and Vera Carstairs, 1991. 'Which Deprivation? A Comparison of Selected Deprivation Indexes.' Journal of Public Health 13(4): 318-326. doi: 10.1093/oxfordjournals.pubmed.a042650.

Norman, Paul and Paul Boyle, 2014. 'Are Health Inequalities between Differently Deprived Areas Evident at Different Ages? A Longitudinal Study of Census Records in England and Wales, 1991-2001.' Health and Place 26: 88-93. doi: 10.1016/j.healthplace.2013.12.010.

Norman, Paul, Paul Boyle, and Philip Rees, 2005. 'Selective Migration, Health, and Deprivation. A Longitudinal Analysis.' Social Science and Medicine 60(12): 2755-2771. doi: 10.1016/j.socscimed.2004.11.008.

OECD and European Observatory on Health Systems and Policies, 2017. United Kingdom Country Health Profile 201\%. State of Health in the EU. Paris: OECD Publishing. doi: 10.1787/9789264283589-en.

Office for National Statistics, 2011. Consultation on Definitions of Avoidable Mortality. London: Her Majesty's Stationery Office.

Oreopoulos, Philip, 2006. 'Estimating Average and Local Average Treatment Effects of Education when Compulsory Schooling Laws Really Matter.' American Economic Review 96(1): 152-175. doi: 10.1257/000282806776157641.

Phelan, Jo C., Bruce G. Link, and Parisa Tehranifar, 2010. 'Social Conditions as Fundamental Causes of Health Inequalities. Theory, Evidence, and Policy Implications.' Journal of Health and Social Behavior 51(Supplement): S28S40. doi: 10.1177/0022146510383498. 
Pingault, Jean-Baptiste, Paul F. O'Reilly, Tabea Schoeler, George B. Ploubidis, Frühling Rijsdijk, and Frank Dudbridge, 2018. 'Using Genetic Data to Strengthen Causal Inference in Observational Research.' Nature Reviews Genetics 19(9): 566-580. doi: 10.1038/s41576-018-0020-3.

Potente, Cecilia, Patrick Präg, and Christiaan Monden, 2022. 'Replication Materials for 'Does Children's Education Improve Parental Health and Longevity? Causal Evidence from Great Britain'.' Open Science Framework doi: $10.17605 /$ OSF.IO/5TQYA.

Powdthavee, Nattavudh, 2010. 'Does Education Reduce the Risk of Hypertension? Estimating the Biomarker Effect of Compulsory Schooling in England.' Journal of Human Capital 4(2): 173-202. doi: 10.1086/657020.

Power, Chris and Jane Elliott, 2006. '1958 British Birth Cohort (National Child Development Study).' International Journal of Epidemiology 35(1): 34-41. doi: 10.1093/ije/dyi183.

Präg, Patrick, Nina-Sophie Fritsch, and Lindsay Richards, 2022. 'Intragenerational Social Mobility and Wellbeing in Great Britain. A Biomarker Approach.' Social Forces 101(1): 665-693. doi: 10.1093/sf/soab153.

Präg, Patrick, Steffen Mau, and Roland Verwiebe, 2010. 'Quality of Life.' In Mau, Steffen and Roland Verwiebe, eds., European Societies. Mapping Structure and Change, pp. 225-260. Bristol: Policy. doi: 10.31235/osf.io/a8qhf.

Präg, Patrick and S.V. Subramanian, 2017. 'Educational Inequalities in SelfRated Health across US States and European Countries.' International Journal of Public Health 62(6): 709-716. doi: 10.1007/s00038-017-0981-6.

Präg, Patrick, Rafael Wittek, and Melinda Mills, 2017. 'The Educational Gradient in Self-Rated Health in Europe. Does the Doctor-Patient Relationship Make a Difference?' Acta Sociologica 60(4): 325-341. doi: 10.1177/0001699316670715.

Rubin, Donald B., 1987. Multiple Imputation for Nonresponse in Surveys. New York: Wiley. doi: 10.1002/9780470316696.

Sabater, Albert and Elspeth Graham, 2016a. 'Intergenerational Exchanges, Children's Education, and Parents' Longevity in Europe.' ESRC Centre for Population Change Working Paper 77.

, 2016b. 'The Role of Children's Education for the Mental Health of Aging Migrants in Europe.' GeroPsych 29(2): 81-92. doi: 10.1024/16629647/a000145. 
Shelton, Nicola, Chris E. Marshall, Rachel Stuchbury, Emily Grundy, Adam Dennett, Jo Tomlinson, Oliver Duke-Williams, ONS staff, and Wei Xun, 2019. 'The Office for National Statistics Longitudinal Study (The LS).' International Journal of Epidemiology 48(2): 383-384g. doi: 10.1093/ije/dyy243.

Silles, Mary A., 2009. 'The Causal Effect of Education on Health. Evidence from the United Kingdom.' Economics of Education Review 28(1): 122-128. doi: 10.1016/j.econedurev.2008.02.003.

Stone, Juliet, Ann Berrington, and Jane Falkingham, 2014. 'Gender, Turning Points, and Boomerangs. Returning Home in Young Adulthood in Great Britain.' Demography 51(1): 257-276. doi: 10.1007/s13524-013-0247-8.

Tomassini, Cecilia, Stamatis Kalogirou, Emily Grundy, Tineke Fokkema, Pekka Martikainen, Marjolein Broese van Groenou, and Antti Karisto, 2004. 'Contacts between Elderly Parents and Their Children in Four European Countries. Current Patterns and Future Prospects.' European Journal of Ageing 1(1): 54-63. doi: 10.1007/s10433-004-0003-4.

Torssander, Jenny, 2013. 'From Child to Parent? The Significance of Children's Education for Their Parents' Longevity.' Demography 50(2): 637-659. doi: 10.1007/s13524-012-0155-3.

_ 2014. 'Adult Children's Socioeconomic Positions and Their Parents' Mortality. A Comparison of Education, Occupational Class, and Income.' Social Science and Medicine 122: 148-156. doi: 10.1016/j.socscimed.2014.10.043.

Tosi, Marco and Marco Albertini, 2019. 'Does Children's Union Dissolution Hurt Elderly Parents? Linked Lives, Divorce and Mental Health in Europe.' European Journal of Population 35(4): 695-717. doi: 10.1007/s10680-0189501-5.

Vollmer, Sebastian, Christian Bommer, Aditi Krishna, Kenneth Harttgen, and S.V. Subramanian, 2017. 'The Association of Parental Education with Childhood Undernutrition in Low- and Middle-Income Countries. Comparing the Role of Paternal and Maternal Education.' International Journal of Epidemiology 46(1): 312-323. doi: 10.1093/ije/dyw133.

Von Hippel, Paul T., 2020. 'How Many Imputations Do You Need? A Two-Stage Calculation Using a Quadratic Rule.' Sociological Methods and Research doi: 10.1177/0049124117747303.

Wang, Haowei, Sae Hwang Han, Kyungmin Kim, and Jeffrey A. Burr, 2022. 'Adult Children's Achievements and Ageing Parents' Depressive Symptoms in China.' Aging and Society 42(4): 896-917. doi: 10.1017/S0144686X20001270. 
White, Ian R. and Patrick Royston, 2009. 'Imputing Missing Covariate Values for the Cox Model.' Statistics in Medicine 28(15): 1982-1998. doi: $10.1002 / \operatorname{sim} .3618$.

White, Ian R., Patrick Royston, and Angela M. Wood, 2011. 'Multiple Imputation using Chained Equations. Issues and Guidance for Practice.' Statistics in Medicine 30: 377-399. doi: 10.1002/sim.4067.

Wolfe, Joseph D., Shawn Bauldry, Melissa A. Hardy, and Eliza K. Pavalko, 2018a. 'Multigenerational Attainments, Race, and Mortality Risk among Silent Generation Women.' Journal of Health and Social Behavior 59(3): 335-351. doi: 10.1177/0022146518784596.

, 2018b. 'Multigenerational Socioeconomic Attainments and Mortality among Older Men. An Adjacent Generations Approach.' Demographic Research 39(26): 719-752. doi: 10.4054/DemRes.2018.39.26.

Wu, Zheng and Margaret J. Penning, 2019. 'Children and the Mental Health of Older Adults in China. What Matters?' Population Research and Policy Review 38(1): 27-52. doi: 10.1007/s11113-018-9495-z.

Yahirun, Jenjira J., Connor M. Sheehan, and Mark D. Hayward, 2016. 'Adult Children's Education and Parents' Functional Limitations in Mexico.' Research on Aging 38(3): 322-345. doi: 10.1177/0164027515620240.

- 2017. 'Adult Children's Education and Changes to Parents' Physical Health in Mexico.' Social Science and Medicine 181: 93-101. doi: 10.1016/j.socscimed.2017.03.034.

Yahirun, Jenjira J., Connor M. Sheehan, and Krysia N. Mossakowski, 2020a. 'Depression in Later Life. The Role of Adult Children's College Education for Older Parents' Mental Health in the United States.' Journals of Gerontology B 75(2): 389-402. doi: 10.1093/geronb/gby135.

Yahirun, Jenjira J., Sindhu Vasireddy, and Mark D. Hayward, 2020b. 'The Education of Multiple Family Members and the Life Course Pathways to Cognitive Impairment.' Journals of Gerontology B 75(7): e113-e128. doi: 10.1093/geronb/gbaa039.

Yang, Lei, Pekka Martikainen, and Karri Silventoinen, 2016. 'Effects of Individual, Spousal, and Offspring Socioeconomic Status on Mortality Among Elderly People in China.' Journal of Epidemiology 26(11): 602-609. doi: 10.2188/jea.JE20150252.

Zimmer, Zachary, Heidi A. Hanson, and Ken R. Smith, 2016. 'Offspring Socioeconomic Status and Parent Mortality Within a Historical Population.' Demography 53(5): 1583-1603. doi: 10.1007/s13524-016-0502-x. 
Zimmer, Zachary, Albert I. Hermalin, and Hui-Sheng Lin, 2002. 'Whose Education Counts? The Added Impact of Adult-Child Education on Physical Functioning of Older Taiwanese.' Journals of Gerontology B 57(1): S23-S32. doi: 10.1093/geronb/57.1.S23.

Zimmer, Zachary, Linda G. Martin, Mary Beth Ofstedal, and Yi-Li Chuang, 2007. 'Education of Adult Children and Mortality of their Elderly Parents in Taiwan.' Demography 44(2): 289-305. doi: 10.1353/dem.2007.0020. 


\section{SUPPLEMENTARY MATERIALS}

\section{Contents}

A Replication materials and data references .......... . 36

B Question wording for longstanding illness and poor self-rated health in ONS-LS . . . . . . . . . . . . . . . . . . 39

C Tables underlying Figures in the main text . . . . . . . . 41

C.1 Empirical Analysis 1: birth cohort . . . . . . . . . . 41

C.2 Empirical Analysis 2: linked census data . . . . . . . . . 41

D Robustness checks .................. . 41

D.1 Empirical Analysis 1: birth cohort . . . . . . . . . . 41

D.2 Empirical Analysis 2: linked census data . . . . . . . 46

\section{A Replication materials and data references}

Analyses shown in this manuscript are fully replicable. Program code for the replication is available on-line (Potente et al., 2022).

Data used in the study are publicly available. The birth cohort data analyzed in this study (Power and Elliott, 2006) as well as the data used for Figure 2 (Mindell et al., 2012) are available from the UK Data Service to registered researchers. The linked census data analyzed in this study (Shelton et al., 2019) are available from the Office of National Statistics (ONS) to accredited researchers after the opening of an approved research project. Further information on how to obtain accredited researcher status is available from the Office of National Statistics.

\section{NCDS (Power and Elliott, 2006) data sets used in Empirical Analy-} sis 1

Bukodi, Erzsébet, 2017. National Child Development Study and 1970 British Cohort Study Educational Qualifications Histories, 1981-2009. London: Center for Longitudinal Studies. doi: 10.5255/UKDA-SN-8127-1.

Center for Longitudinal Studies, 2008a. National Child Development Study. Sweep 6, 1999-2000. London: Joint Center for Longitudinal Research, 2nd edition. doi: 10.5255/UKDA-SN-5578-1.

,2008b. National Child Development Study. Sweep 7, 2004-5. Colchester: UK Data Service, 3rd edition. doi: 10.5255/UKDA-SN-5579-1.

, 2012. National Child Development Study. Sweep 8, 2008-9. Colchester:

UK Data Service, 3rd edition. doi: 10.5255/UKDA-SN-6137-2. 
2014. National Child Development Study. Childhood Data, Sweeps 0-3, 1958-74. London: National Birthday Trust Fund. doi: 10.5255/UKDA-SN$5565-2$

— , 2015. National Child Development Study. Sweep 9, 2013. London: UK Data Service. doi: 10.5255/UKDA-SN-7669-1.

Power, Chris and Jane Elliott, 2006. '1958 British Birth Cohort (National Child Development Study).' International Journal of Epidemiology 35(1): 34-41. doi: $10.1093 / \mathrm{ije} /$ dyi183.

\section{HSE (Mindell et al., 2012) data sets used in Figure 2}

Joint Health Surveys Unit of Social and Community Planning Research and University College London, 2017a. Health Survey for England 1994. London: UK Data Service, 5th edition. doi: 10.5255/UKDA-SN-3640-2.

- 2017b. Health Survey for England 1995. London: UK Data Service, 5th edition. doi: 10.5255/UKDA-SN-3796-2.

— 2017c. Health Survey for England 1996. London: UK Data Service, 5th edition. doi: 10.5255/UKDA-SN-3886-2.

2017d. Health Survey for England 1997. London: UK Data Service, 4th edition. doi: 10.5255/UKDA-SN-3979-2.

Mindell, Jennifer, Jane P. Biddulph, Vasant Hirani, Emanuel Stamatakis, Rachel Craig, Susan Nunn, and Nicola Shelton, 2012. 'The Health Survey for England.' International Journal of Epidemiology 41(6): 1585-1593. doi: 10.1093/ije/dyr199.

Natcen Social Research and Royal Free and University College Medical School, Department of Epidemiology and Public Health, 2015. Health Survey for England 2010. London: UK Data Service, 3rd edition. doi: 10.5255/UKDASN-6986-3.

Natcen Social Research and University College London, Department of Epidemiology and Public Health, 2014. Health Survey for England 2012. London: UK Data Service. doi: 10.5255/UKDA-SN-7480-1.

— - 2015. Health Survey for England 2013. London: UK Data Service. doi: 10.5255/UKDA-SN-7649-1.

National Center for Social Research and University College London, Department of Epidemiology and Public Health, 2010a. Health Survey for England 1999. London: UK Data Service, 4th edition. doi: 10.5255/UKDA-SN-4365-1. 
_ 2010b. Health Survey for England 2001. London: UK Data Service, 3rd edition. doi: 10.5255/UKDA-SN-4628-1.

— - 2010c. Health Survey for England 2004. London: UK Data Service, 2nd edition. doi: 10.5255/UKDA-SN-5439-1.

— - 2010d. Health Survey for England 200\%. London: UK Data Service, 2nd edition. doi: 10.5255/UKDA-SN-6112-1.

—_ 2011. Health Survey for England 2006. London: UK Data Service, 4th edition. doi: 10.5255/UKDA-SN-5809-1.

— - 2013. Health Survey for England 2008. London: UK Data Service, 4th edition. doi: 10.5255/UKDA-SN-6397-2.

Office of Population Censuses and Surveys, Social Survey Division, 1997a. Health Survey for England 1991-2. Combined Data File. London: UK Data Service, 2nd edition. doi: 10.5255/UKDA-SN-3238-1.

— , 1997b. Health Survey for England 1993. London: UK Data Service, 2nd edition. doi: 10.5255/UKDA-SN-3316-1.

University College London, Department of Epidemiology and Public Health and National Center for Social Research, 2010a. Health Survey for England 1998. London: UK Data Service, 5th edition. doi: 10.5255/UKDA-SN-4150-1.

_ 2010b. Health Survey for England 2000. London: UK Data Service, 4th edition. doi: 10.5255/UKDA-SN-4487-1.

— - 2010c. Health Survey for England 2002. London: UK Data Service, 2nd edition. doi: 10.5255/UKDA-SN-4912-1.

— - 2010d. Health Survey for England 2003. London: UK Data Service, 2nd edition. doi: 10.5255/UKDA-SN-5098-1.

- 2011. Health Survey for England 2005. London: UK Data Service, 3rd edition. doi: 10.5255/UKDA-SN-5675-1.

— - 2013. Health Survey for England 2011. London: UK Data Service. doi: 10.5255/UKDA-SN-7260-1.

- 2015. Health Survey for England 2009. London: UK Data Service, 3rd edition. doi: 10.5255/UKDA-SN-6732-2. 


\section{B Question wording for longstanding illness and poor self- rated health in ONS-LS}

The census question wording for longstanding illness and poor self-rated health has varied over time, in Table A1 we show the exact wording of the question and response options. Parentheses behind response options show how we coded the responses for analysis.

Table A1: Wording of health questions in the 1991-2011 census forms

\begin{tabular}{|c|c|c|}
\hline Year & Long-term illness & Self-rated health \\
\hline 2011 & $\begin{array}{l}\text { 'Are your day-today activities } \\
\text { limited because of a health } \\
\text { problem or disability which has } \\
\text { lasted, or is expected to last, at } \\
\text { least } 12 \text { months? Include } \\
\text { problems related to old age.' } \\
\text { - 'Yes, limited a lot.' (1) } \\
\text { - 'Yes, limited a little.' (1) } \\
\text { - 'No.' (0) }\end{array}$ & $\begin{array}{l}\text { 'How is your health in general?' } \\
\text { - 'Very good.' (0) } \\
\text { - 'Good.' (0) } \\
\text { - 'Fair.' (0) } \\
\text { - 'Bad.' (1) } \\
\text { - 'Very bad.' (1) }\end{array}$ \\
\hline 2001 & $\begin{array}{l}\text { 'Do you have any long-term } \\
\text { illness, health problem, or } \\
\text { disability which limits your } \\
\text { daily activities or the work you } \\
\text { can do. Include problems which } \\
\text { are due to old age. } \\
\text { - 'Yes.' (1) } \\
\text { - 'No.' (0) }\end{array}$ & $\begin{array}{l}\text { 'Over the last twelve months } \\
\text { would you say your health has } \\
\text { on the whole been:' } \\
\text { - 'Good' (0) } \\
\text { - 'Fairly good' (0) } \\
\text { - 'Not good?' (1) }\end{array}$ \\
\hline
\end{tabular}


Table A1: Wording of health questions in the 1991-2011 census forms (cont'd)

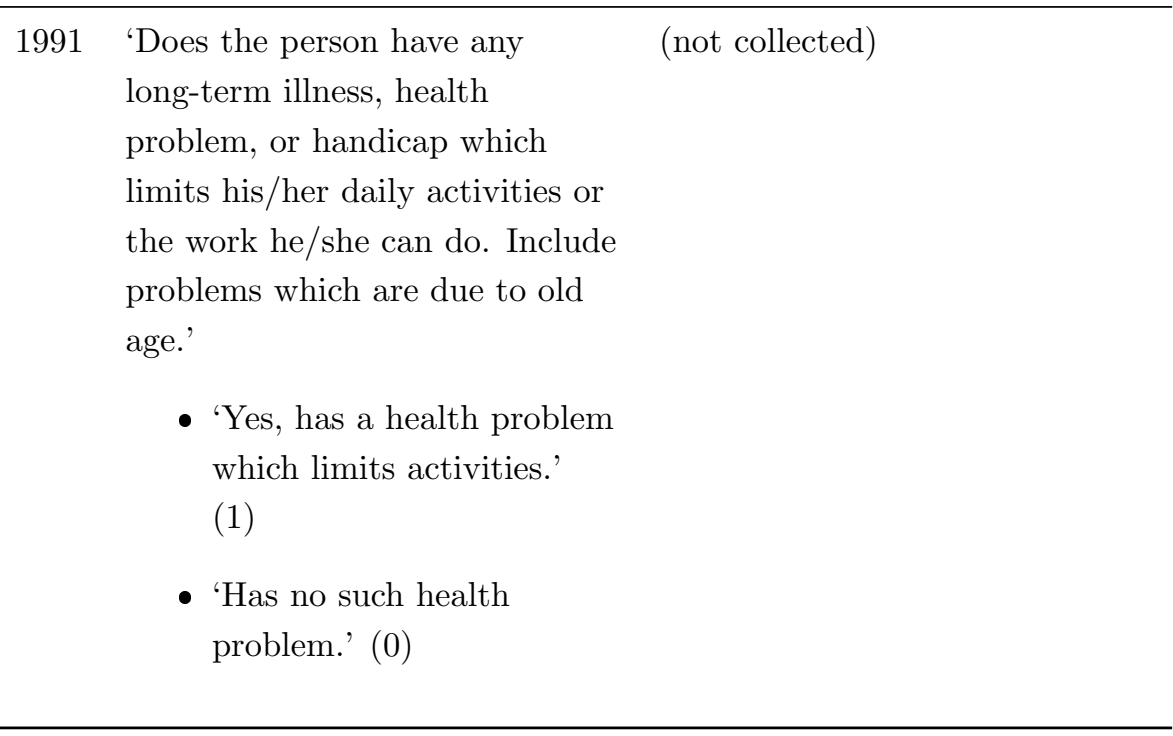




\section{Tables underlying Figures in the main text}

\section{C.1 Empirical Analysis 1: birth cohort}

Table A2 shows the full models underlying Figure 1 in the main text.

Table A2: Cox regression for parental survival, hazard ratios

\begin{tabular}{|c|c|c|c|c|}
\hline & \multicolumn{2}{|c|}{ Mothers } & \multicolumn{2}{|c|}{ Fathers } \\
\hline & $(1)$ & $(2)$ & $(1)$ & $(2)$ \\
\hline Female child (ref. male) & $1.11^{* *}$ & $1.11^{* *}$ & $1.09^{* *}$ & $1.09^{* *}$ \\
\hline Child born out of wedlock (ref. not) & $1.58^{* * *}$ & $1.57^{* * *}$ & 1.06 & 1.06 \\
\hline Age at birth & $1.03^{* * *}$ & $1.03^{* * *}$ & $1.03^{* * *}$ & $1.02^{* * *}$ \\
\hline Age child left education (years) & $0.94^{* * *}$ & $0.97^{* *}$ & $0.95^{* * *}$ & $0.98^{*}$ \\
\hline \multicolumn{5}{|l|}{ Social class parents (ref. I) } \\
\hline $\mathrm{II}+\mathrm{IVa}$ & & 1.01 & & 1.01 \\
\hline III & & 1.06 & & 1.07 \\
\hline $\mathrm{IVb}+\mathrm{c}$ & & 1.02 & & 1.01 \\
\hline $\mathrm{V}$ & & 1.08 & & 1.07 \\
\hline VI & & $1.41^{* * *}$ & & $1.17^{*}$ \\
\hline VII & & $1.35^{* *}$ & & $1.31^{* * *}$ \\
\hline \multicolumn{5}{|l|}{ Age father left education (ref. $13-15$ y.) } \\
\hline $16-17$ у. & & 1.02 & & 0.93 \\
\hline $18-19$ y. & & 0.88 & & 0.91 \\
\hline $20+\mathrm{y}$ & & 0.90 & & 0.94 \\
\hline \multicolumn{5}{|l|}{ Age mother left education (ref. $13-15$ y.) } \\
\hline $16-17$ у. & & 0.93 & & $0.91^{*}$ \\
\hline $18-19 \mathrm{y}$. & & 0.89 & & $0.84^{*}$ \\
\hline $20+\mathrm{y}$ & & 0.84 & & $0.79^{*}$ \\
\hline$N$ & 7,233 & 7,233 & 7,034 & 7,034 \\
\hline$N_{\text {Events }}$ & 3,139 & 3,139 & 4,602 & 4,602 \\
\hline
\end{tabular}

\section{C.2 Empirical Analysis 2: linked census data}

Table A3 shows estimates underlying Figure 4 in the main text.

\section{Robustness checks}

\section{D.1 Empirical Analysis 1: birth cohort}

In Table A4 and A5, we show six key robustness checks of our results.

First, we assessed the role of missing values by comparing the results to those obtained from using multiple imputation with chained equations (MICE, White et al., 2011). We imputed the following variables: mother's/father's age at birth with linear regression, child sex and child born out of wedlock with a logit link, education of the father, mother, and child with an ordered logit 


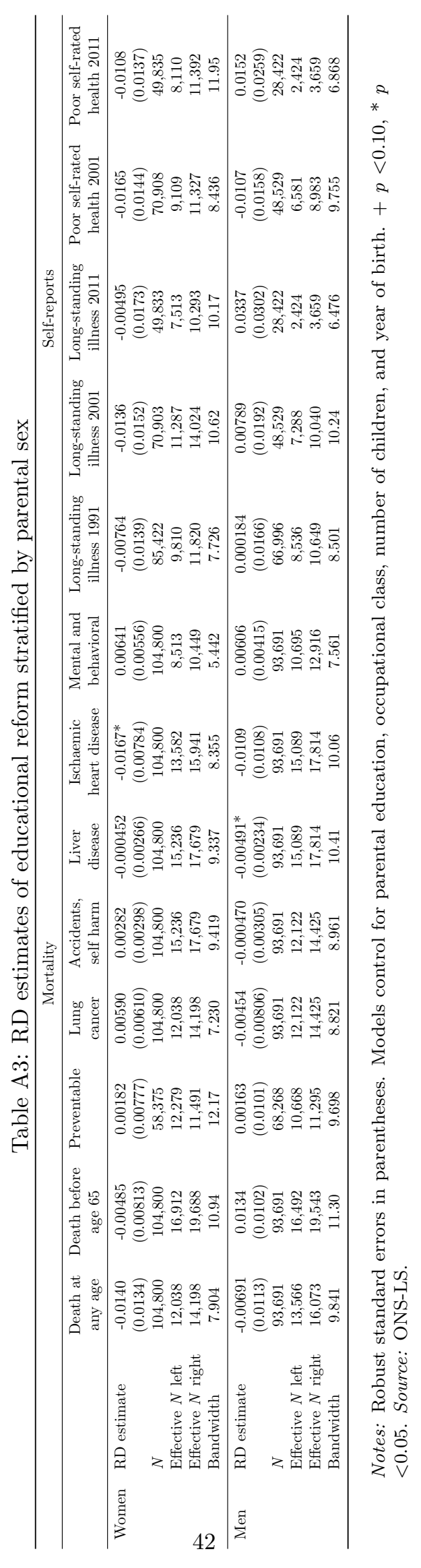


link, and parental social class with a multinomial logit link. We use as auxiliary variables the indicator dummy for the death of the father and the mother plus the Nelson-Aalen estimate of the cumulative hazards for fathers and mothers, as suggested by White and Royston (2009). For determining $m$, the number of imputations, we made use of Von Hippel's (2020) algorithm, which suggested between 3 and 37 imputations for our models. We used 37 imputations for every model. We ran models on the imputed data and combined the resulting estimators using the rules stated by Rubin (1987, ch. 3).

Second, we restricted the sample restricted to birth cohort members who were lived in England and Wales at age 16 (excluding those living in Scotland) in order to make it comparable to the second part of the analysis which focuses on a schooling reform that only took place in England and Wales. In all cases, the magnitude of the coefficients changes slightly but the direction of the associations stays the same.

Third, we assessed the proportional hazard assumption using Schoenfeld residuals, which suggested that the assumption might be violated for the adult children's education variable. Substantively, this means that the association of children's education and parental longevity varies over time and that the associations shown in Figure 1 show a rough average of the strength of the association over time. Models including the interaction of children's education with time however lead to the same substantive conclusion of an association between children's education and parental longevity, which is attenuated when accounting for parental class and education.

Fourth, we further test the robustness of our results using a parametric acceleration failure time survival model following a Weibull distribution. This model offers an alternative to the Cox model by assuming that the effect of the covariates is proportional to the survival time (and not to the hazard as in the Cox model). Using this specification the time ratios associated with an additional year of children's education shows an increase in survival by $1.4 \%$ for mothers and by $0.8 \%$ for fathers in the full covariates model.

Fifth, we test the robustness of the results to families with more than one offspring by including an indicator of whether the respondent is single child or not at age 16. Unfortunately, the data do not contain the educational level for the other siblings and therefore we could not perform additional robustness checks on different operationalizations for the educational level of the siblings. The results presented in Figure A1 shows a similar conclusion as in the main analysis.

Finally, we include a robustness test of the results using categorical education variable to account for a possible non-linear correlation. The results, shown in Figure A2, yield a similar conclusion to the linear analysis. 


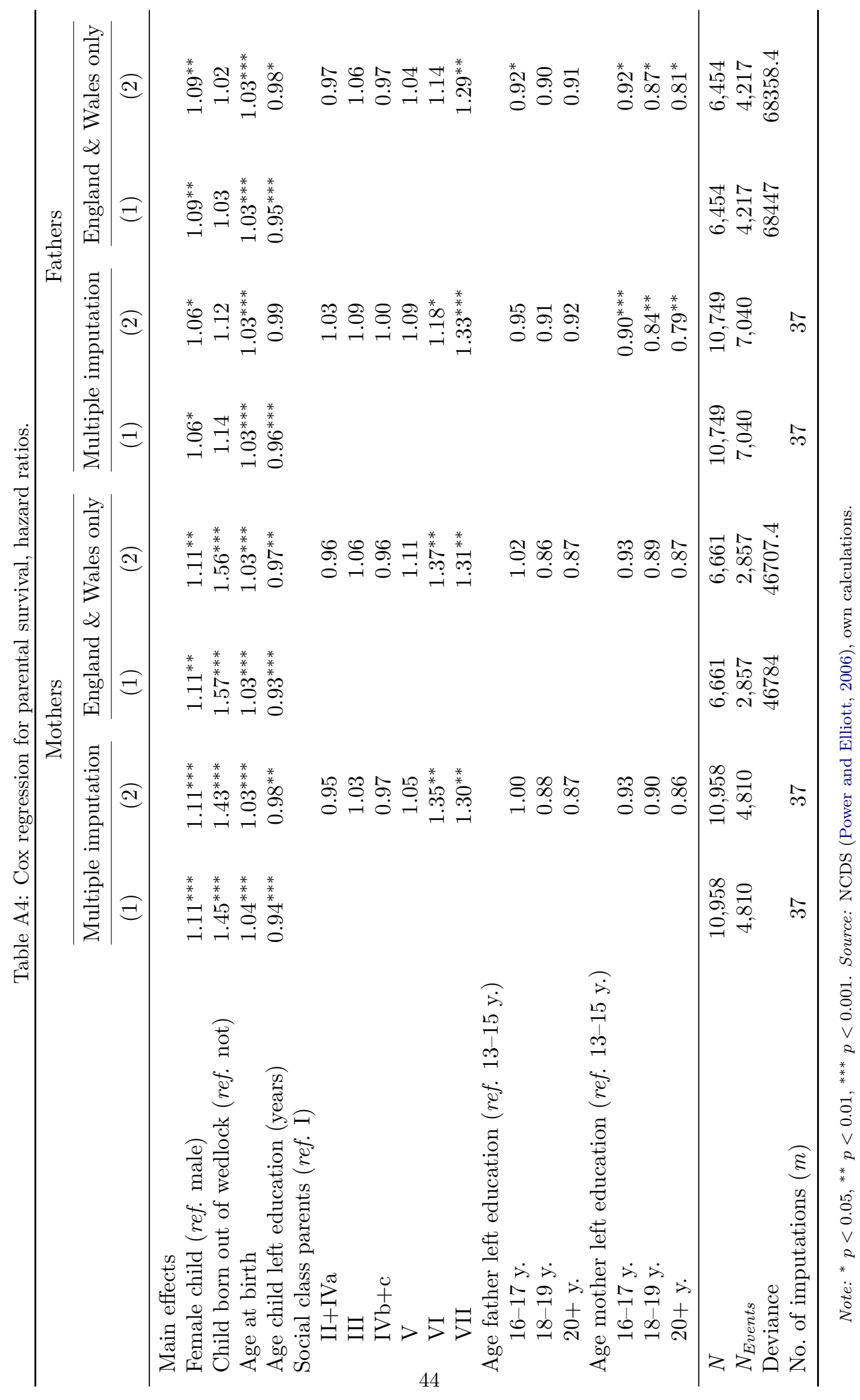




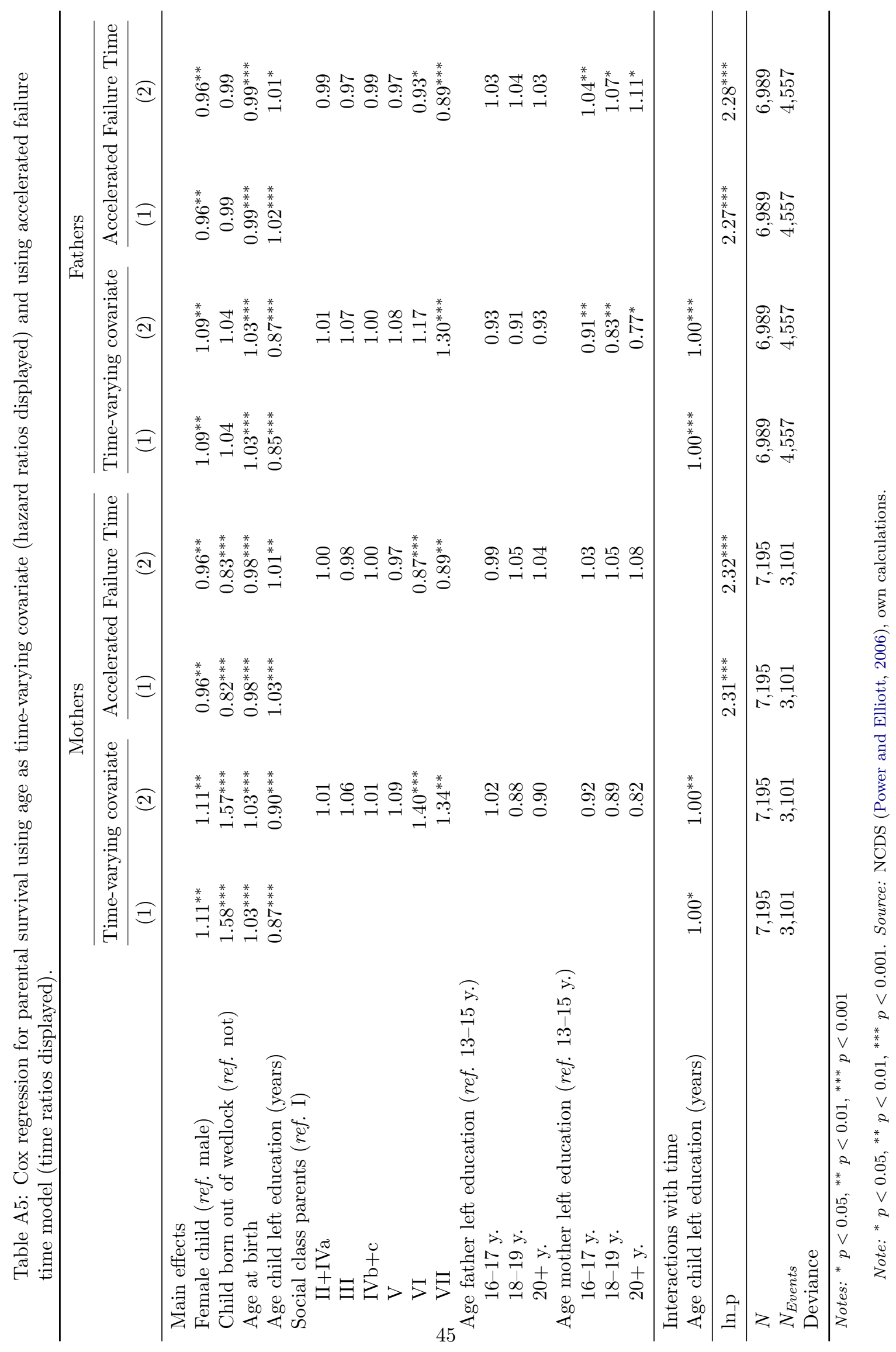




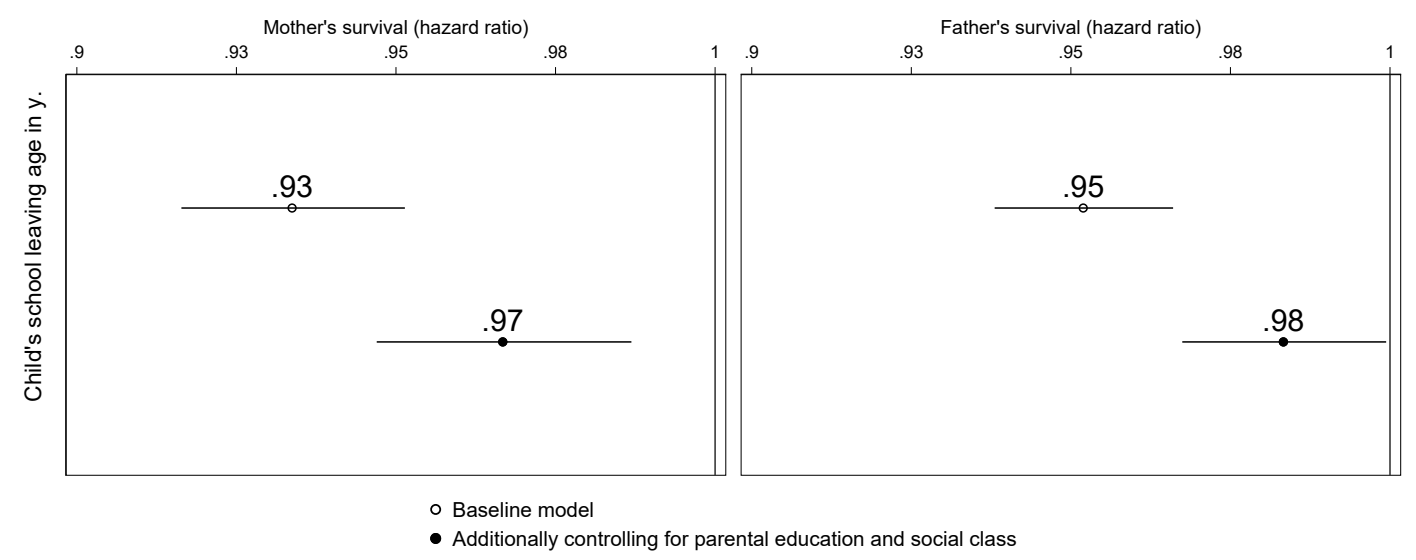

Figure A1: Cox proportional hazard models for the association between children's education and parental mortality including binary variable indicating whether the child is single child or not.

Notes: Error bars denote $95 \%$ confidence interval based on robust standard errors. Controls comprise parental education, number of children, and year of birth. Source: NCDS (Power and Elliott, 2006), own calculations.

\section{D.2 Empirical Analysis 2: linked census data}

Occupational class, education, and area deprivation as stratifying variables Figures ?? and A4 as well as Tables A6, A8, and A9 show estimates stratified by parental occupational class, parental education, and by level of area deprivation.

Parental occupational class is indicated by the registrar-general's class scheme (Connelly et al. 2016), comprising classes I/II ("Professional occupations" and "Managerial and technical occupations"), III Non-manual ("Skilled non-manual occupations"), III Manual ("Skilled manual occupation"), IV and V ("Partlyskilled occupations" and "Unskilled occupations"). Class was derived from respondent's occupation in 1971. Women married at the time of the census have been assigned the occupational class of their husband if a husband was present, otherwise their own occupational class.

Parental education is taken from the 1971 census form, which has two questions on education, one question asking whether a respondent has the following degrees: 1) GCE A-level or Higher School Certificate (HSC), 2) Higher grade of Scottish Certificate of Education (SCE) or Higher grade of Scottish Leaving Certificate (SLC), 3) Ordinary National Certificate (ONC) or Ordinary National Diploma (OND), or 4) None of these. The second question requests to list any of the following qualifications: Higher National Certificate (HNC) or Higher National Diploma (HND), Nursing qualifications, Teaching qualifications, Degrees, Graduate or corporate membership of professional institutions, and Any other 


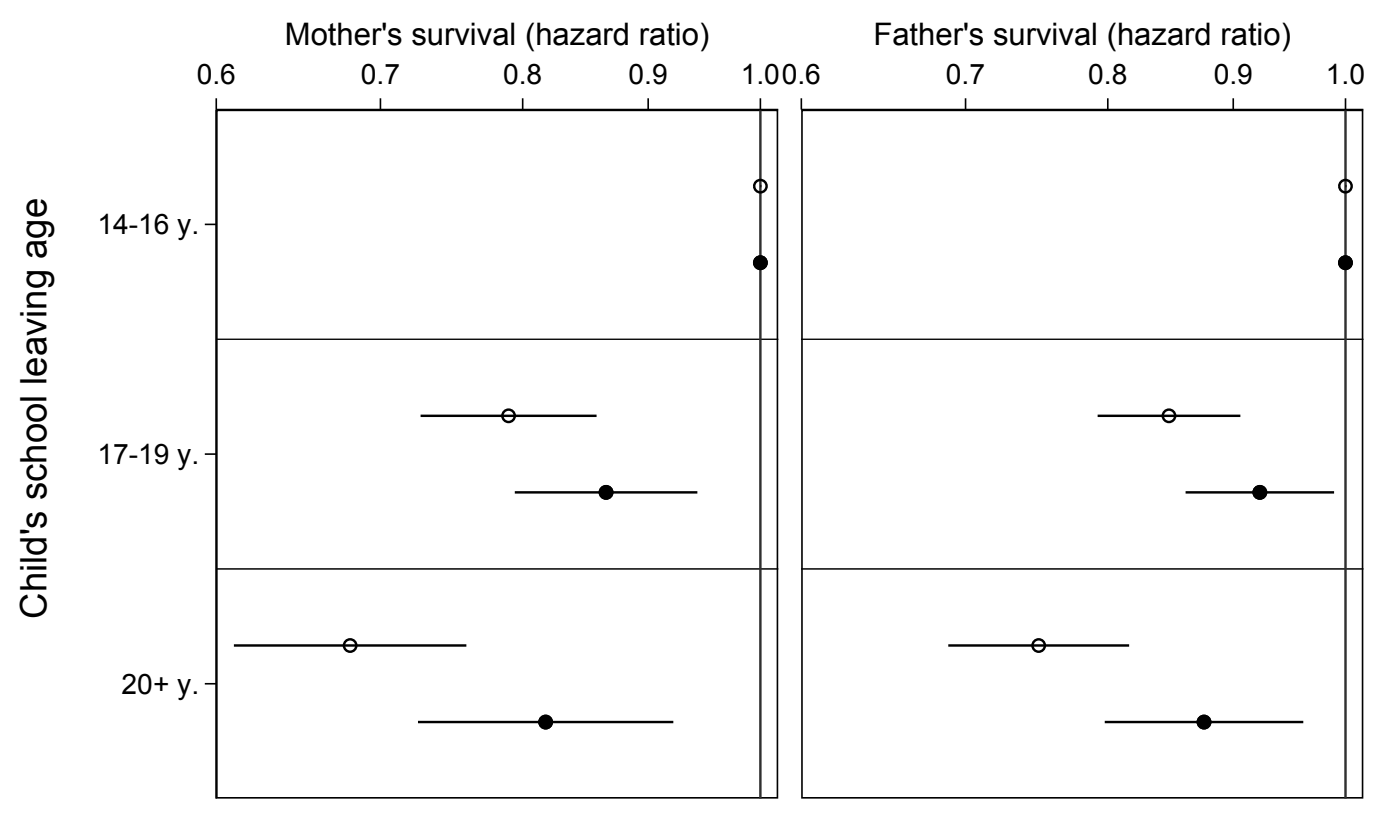

- Baseline model • Additionally controlling for parental education and social class

Figure A2: Cox proportional hazard models for the association between children's education and parental mortality using categorical specification of children's education.

Notes: Error bars denote 95\% confidence interval based on robust standard errors. Controls comprise parental education, number of children, and year of birth. Source: NCDS (Power and Elliott, 2006), own calculations. 


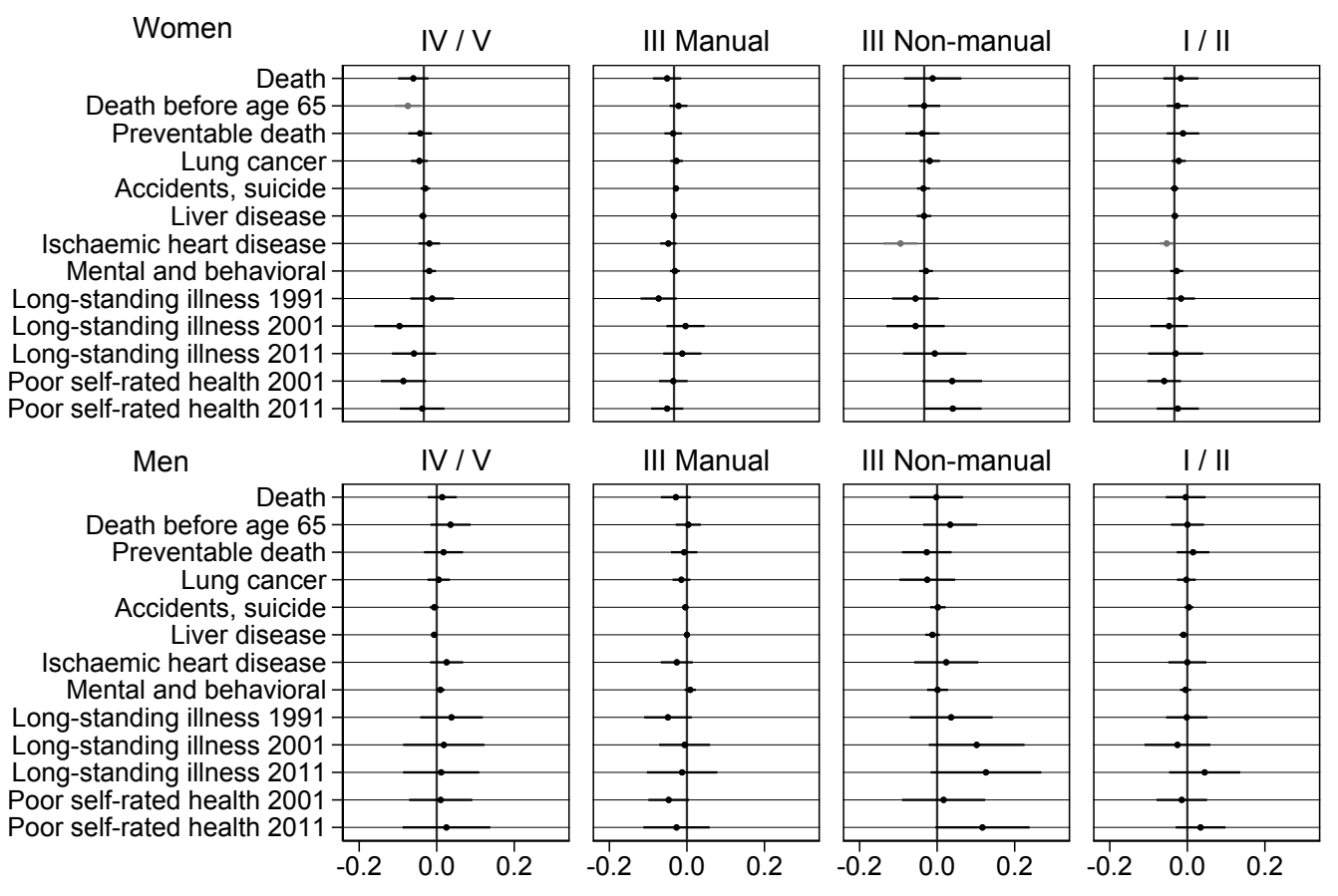

Figure A3: RD estimates of educational reform stratified by parental sex and parental occupational class

Notes: Error bars denote $95 \%$ confidence interval based on robust standard errors. Controls comprise parental education, number of children, and year of birth. Estimates shown in Table A6. Source: ONS-LS (Shelton et al., 2019), own calculations. 


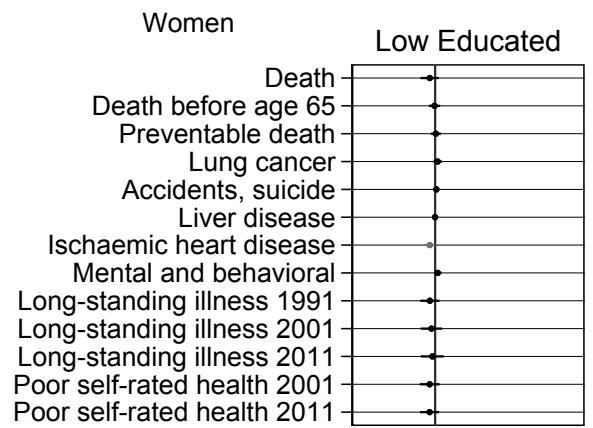

Men

Low Educated

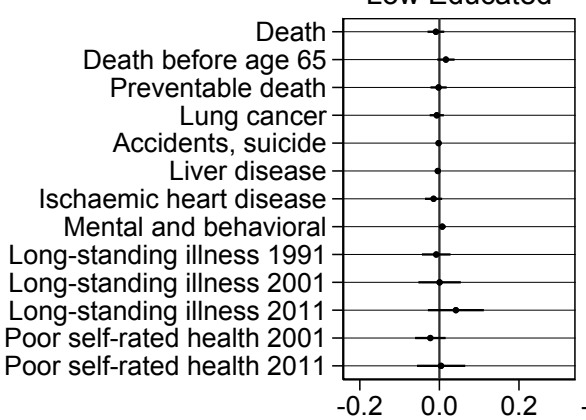

$\begin{array}{lll}-0.2 & 0.0 & 0.2\end{array}$
High Educated

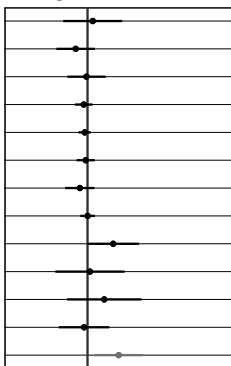

High Educated

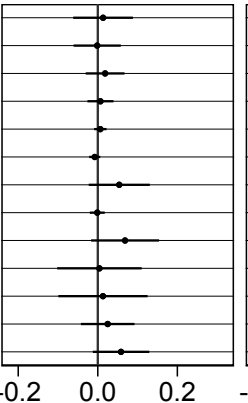

Deprived Areas Non-deprived Areas

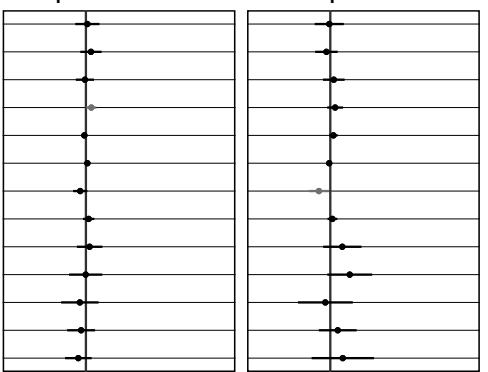

Deprived Areas Non-deprived Areas
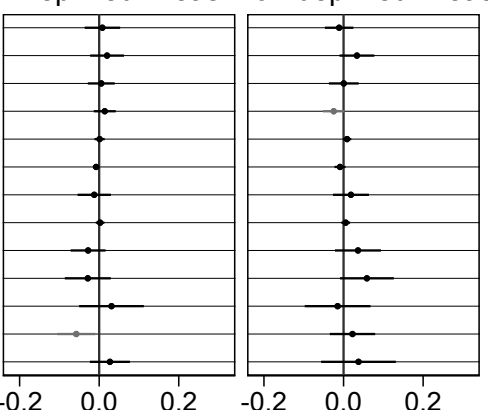

Figure A4: RD estimates of educational reform stratified by parental sex and parental education and area deprivation

Notes: Error bars denote 95\% confidence interval based on robust standard errors. Controls comprise parental education (only for area deprivation model), occupational class, number of children and year of birth. Estimates shown in Table A8 and A9. Source: ONS-LS (Shelton et al., 2019), own calculations. 


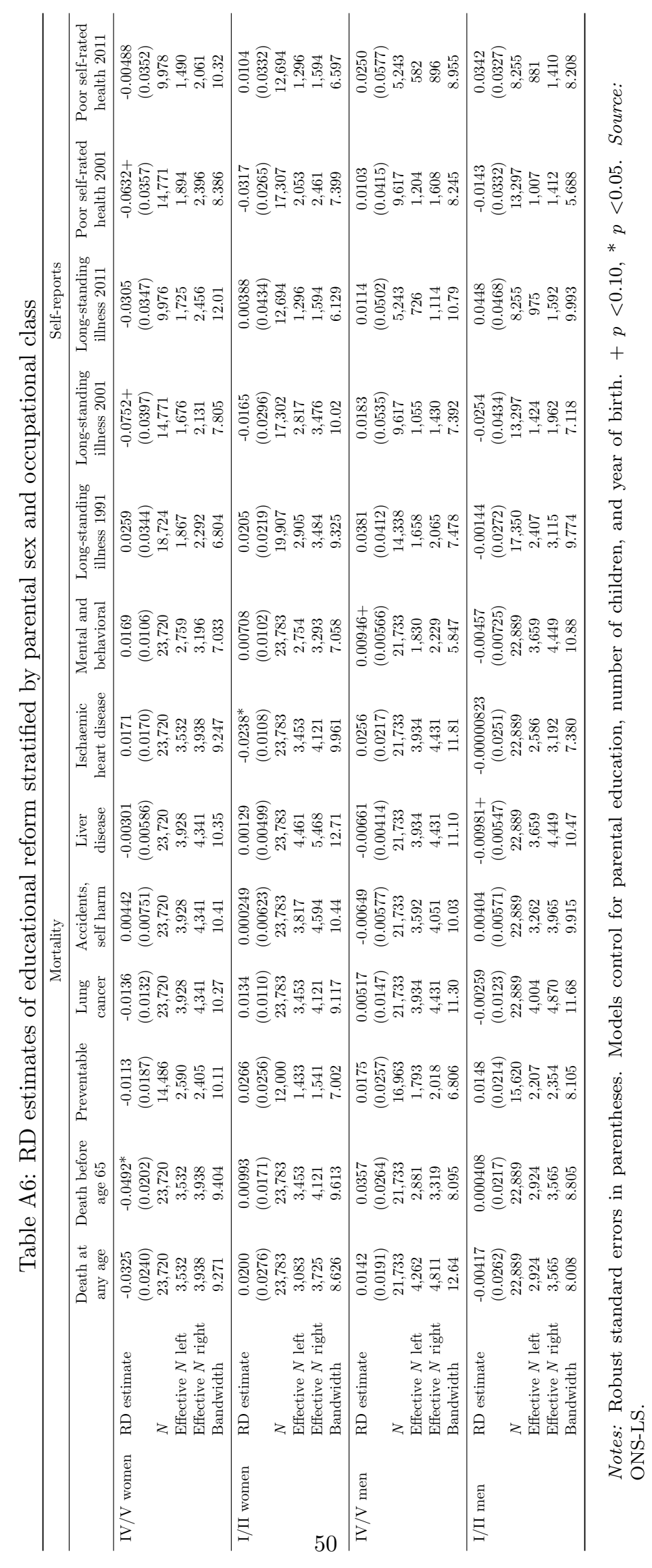


professional or vocational qualifications. For our analyses, we count affirmative responses to option 4) in the first question as being lower educated (which applies to ca. 90 per cent of the sample) and any other response as being higher educated.

In addition, we stratify the analyses by quintiles of the Carstairs index of deprivation (Morris and Carstairs, 1991), comparing the two lowest quintiles with the top-two quintiles (Norman and Boyle, 2014). The index is a wellestablished geographical measure of material deprivation and is based on four variables, namely regional unemployment, overcrowded households, households without cars, and households with a household head in a low occupational class. The Carstairs Index has previously been used in conjunction with the ONS-LS (Boyle et al., 2004; Norman and Boyle, 2014; Norman et al., 2005). The index is calculated at the ward level, which on average comprise 5,500 residents, and of which there are 7,707 in England and 881 in Wales. We measure the Carstairs index at the latest census for sample members who are alive at the end of the follow-up period, otherwise at the census closest to their time of death.

Among low-educated women and women in deprived areas, we do not find the same health benefits of more educated children that we observed for occupational class. A comparison of findings for occupational class with those for parental education and area deprivation, reveals that our findings are sensitive to the chosen measure of socio-economic position (Figures ?? and A4). Figure A4 contains an unexpected result. Children's education reduces the risk of dying from ischaemic heart disease only for lower-educated women $(-1.9 \%$, $-3.5 \%-0.2 \%$ ), but children's education increases the risk of higher-educated women to report poor self-rated health in 2011 (9.1\%, 1.8-16.5\%).

The right-hand panels of Figure A4 show results by area deprivation, suggesting that children's education reduces the risk of ischaemic heart disease $(-3.4 \%,-6.4 \%--0.5 \%)$ of women living in non-deprived areas (which is in line with the finding for occupational class but not education). For women in deprived areas children's education increases the risk of dying from lung cancer $(1.6 \%, 0.1 \%-3.2 \%)$. For men, stratifying by area deprivation yields two other findings: Educated children reduce the risk of men in deprived areas to report poor self-rated health in $2001\left(-5.8 \%,-10.5 \%^{--1.1 \%}\right)$ and reduce the risk of dying from lung cancer in non-deprived areas $(-2.5 \%,-5.2 \%-0.2 \%)$.

Number of children as stratifying variable Table A7 presents models stratified by the number of children parents have. The rational for this robustness check is that effects might be especially pronounced among parents with only one child affected by the reform rather than among parents with more children, some of whom will not be affected by the reform. This robustness check did not reveal any significant effects, which is in line with our overall findings. 
Table A7: RD estimates of educational reform stratified by sex and number of children

\begin{tabular}{llcccccc}
\hline & & \multicolumn{3}{c}{ Death at any age } & \multicolumn{3}{c}{ Death before age 65 } \\
& & Singleton & 2 children & $3+$ children & Singleton & 2 children & $3+$ children \\
\hline \multirow{2}{*}{ Women } & RD estimate & -0.0262 & -0.00259 & -0.00999 & 0.0122 & -0.00701 & -0.00621 \\
& & $(0.0387)$ & $(0.0235)$ & $(0.0122)$ & $(0.0314)$ & $(0.0136)$ & $(0.00911)$ \\
& & 8,516 & 31,514 & 64,770 & 8,516 & 31,514 & 64,770 \\
& Effective $N$ left & 1,197 & 3,905 & 12,583 & 1,197 & 4,881 & 12,583 \\
& Effective $N$ right & 1,270 & 4,509 & 15,045 & 1,270 & 5,658 & 15,045 \\
& Bandwidth & 9.980 & 8.079 & 12.63 & 9.056 & 10.53 & 12.20 \\
\hline \multirow{2}{*}{ Men } & RD estimate & 0.0270 & -0.00226 & $-0.0217+$ & 0.0344 & 0.00804 & 0.0143 \\
& & $(0.0340)$ & $(0.0176)$ & $(0.0127)$ & $(0.0387)$ & $(0.0181)$ & $(0.0126)$ \\
& $N$ & 7,327 & 28,743 & 57,621 & 7,327 & 28,743 & 57,621 \\
& Effective $N$ left & 1,321 & 4,770 & 9,529 & 950 & 4,359 & 10,401 \\
& Effective $N$ right & 1,351 & 5,788 & 11,321 & 1,020 & 5,264 & 12,404 \\
& Bandwidth & 11.90 & 11.94 & 10.39 & 8.066 & 10.31 & 11.91 \\
\hline
\end{tabular}

Notes: Robust standard errors in parentheses. Models control for parental education, occupational class, and year of birth. $+p<0.10{ }^{*} p<0.05$. Source: ONS-LS, (Shelton et al., 2019), own calculations.

Different bandwidths Table A10 investigates the effects of choosing different bandwidths around the threshold date. The results remain the same when different bandwidths are selected, demonstrating low sensitivity to the bandwidth chosen.

Power analysis In order to check we have sufficient statistical power for our analyses, we report the regression discontinuity power analysis implemented following Cattaneo et al. (2019). The estimated power analysis uses the optimal bandwidth, local parametric regression, bias-correction, and robust standard errors specified by Calonico et al. (2014). Table A11 provides the power estimates for $T=1$ which represents effects equal to half the standard deviation of the outcome for the untreated with a statistical significance level of 0.05 . From Table A11, we observe that the power levels are all 1.00 across all of the outcomes for a medium-size effect. These results are greater than the common power threshold of 0.80 . Moreover, we run additional analysis to examine the power even for smaller effect sizes. From Tables A12 and A13 we observe that our analyses are able to detect smaller effects such as $T=0.5(0.25 \sigma)$ and $T=0.8(0.4 \sigma)$ with a high level of confidence. Only with $T=0.2(0.1 \sigma)$ we observe that some outcome could be slightly underpowered, but this represents extremely small effects. All the power analyses are implemented in Stata using the package 'rdpower' (Cattaneo et al., 2019). 


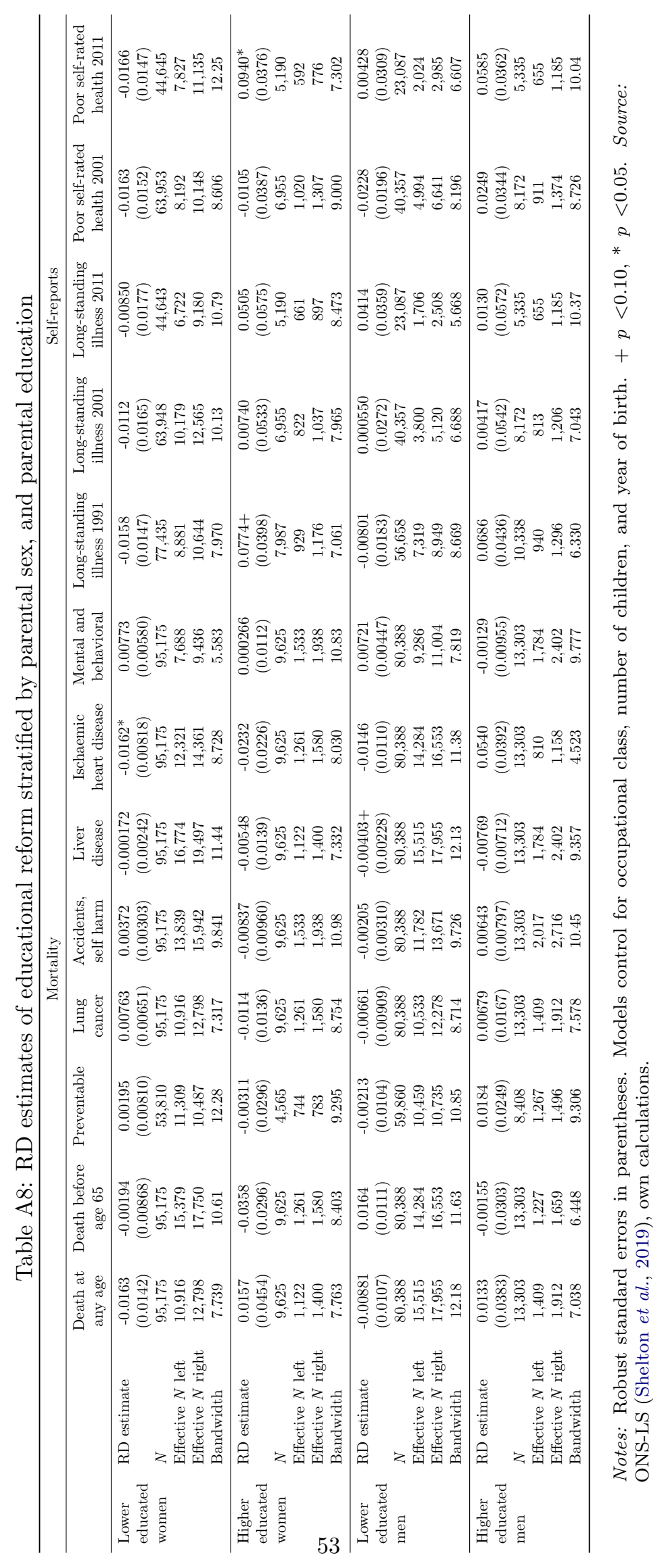




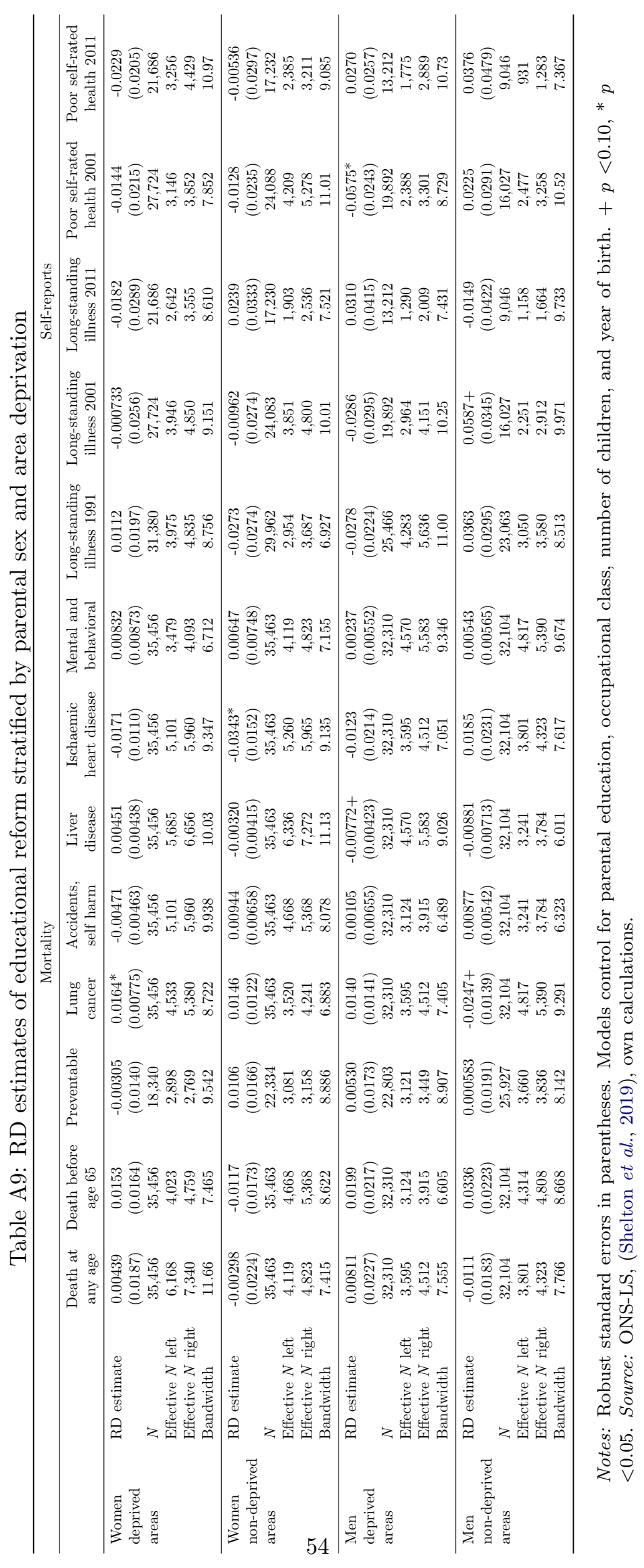


Table A10: RD estimates of educational reform stratified by sex for different bandwidths

\begin{tabular}{|c|c|c|c|c|c|c|}
\hline & \multicolumn{2}{|c|}{ Bandwidth 4} & \multicolumn{2}{|c|}{ Bandwidth 8} & \multicolumn{2}{|c|}{ Bandwidth 12} \\
\hline & RD estimate & SE & RD estimate & SE & RD estimate & SE \\
\hline \multicolumn{7}{|l|}{ Women } \\
\hline Death at any age & 0.0074 & $(0.0214)$ & -0.0142 & $(0.0134)$ & -0.0109 & $(0.0108)$ \\
\hline Death before age 65 & 0.0105 & $(0.0158)$ & -0.0029 & $(0.00965)$ & -0.0049 & $(0.00775)$ \\
\hline Lung cancer & 0.0105 & $(0.0094)$ & 0.0052 & $(0.0058)$ & 0.0055 & $(0.0047)$ \\
\hline Accidents, self harm & 0.0030 & $(0.0053)$ & 0.0036 & $(0.0033)$ & 0.0018 & $(0.0026)$ \\
\hline Liver disease & 0.0055 & $(0.0048)$ & -0.0001 & $(0.0029)$ & -0.0004 & $(0.0023)$ \\
\hline Ischaemic heart disease & -0.0167 & $(0.0132)$ & $-0.0166^{*}$ & $(0.0081)$ & $-0.0163^{*}$ & $(0.0064)$ \\
\hline Mental and behavioral & 0.0085 & $(0.0072)$ & 0.0056 & $(0.0046)$ & 0.0007 & $(0.0038)$ \\
\hline Preventable & -0.0171 & $(0.0165)$ & -0.0004 & $(0.0100)$ & 0.0018 & $(0.0079)$ \\
\hline Long-standing illness 1991 & 0.0057 & $(0.0220)$ & -0.0078 & $(0.0138)$ & -0.0119 & $(0.0111)$ \\
\hline Long-standing illness 2001 & 0.0208 & $(0.0283)$ & -0.0093 & $(0.0177)$ & -0.0141 & $(0.0143)$ \\
\hline Long-standing illness 2011 & 0.0074 & $(0.0320)$ & -0.0007 & $(0.0197)$ & -0.0050 & $(0.0159)$ \\
\hline Poor self-rated health 2001 & -0.0052 & $(0.0239)$ & -0.0176 & $(0.0149)$ & -0.0144 & $(0.0121)$ \\
\hline Poor self-rated health 2011 & 0.0085 & $(0.0274)$ & -0.0084 & $(0.0170)$ & -0.0107 & $(0.0137)$ \\
\hline \multicolumn{7}{|l|}{ Men } \\
\hline Death at any age & -0.0209 & $(0.0205)$ & -0.0067 & $(0.0127)$ & -0.0057 & $(0.0101)$ \\
\hline Death before age 65 & 0.0046 & $(0.0195)$ & 0.0150 & $(0.0123)$ & 0.0134 & $(0.0099)$ \\
\hline Lung cancer & -0.0086 & $(0.0139)$ & -0.0053 & $(0.0085)$ & -0.0067 & $(0.0068)$ \\
\hline Accidents, self harm & 0.0013 & $(0.0053)$ & 0.0001 & $(0.0032)$ & -0.0009 & $(0.0026)$ \\
\hline Liver disease & -0.0071 & $(0.0052)$ & $-0.0048+$ & $(0.0028)$ & $-0.0045^{*}$ & $(0.0022)$ \\
\hline Ischaemic heart disease & -0.0106 & $(0.0200)$ & -0.0067 & $(0.0123)$ & -0.0131 & $(0.0098)$ \\
\hline Mental and behavioral & $0.0106+$ & $(0.0063)$ & 0.0061 & $(0.0041)$ & 0.0051 & $(0.0032)$ \\
\hline Preventable & $0.0345^{*}$ & $(0.0174)$ & 0.0041 & $(0.0111)$ & -0.0017 & $(0.0091)$ \\
\hline Long-standing illness 1991 & -0.0340 & $(0.0280)$ & -0.0015 & $(0.0174)$ & 0.0001 & $(0.0138)$ \\
\hline Long-standing illness 2001 & -0.0466 & $(0.0359)$ & 0.0037 & $(0.0222)$ & 0.0079 & $(0.0177)$ \\
\hline Long-standing illness 2011 & 0.0572 & $(0.0436)$ & 0.0257 & $(0.0269)$ & 0.0127 & $(0.0217)$ \\
\hline Poor self-rated health 2001 & -0.0068 & $(0.0284)$ & -0.0164 & $(0.0177)$ & -0.0080 & $(0.0142)$ \\
\hline Poor self-rated health 2011 & 0.0043 & $(0.0391)$ & 0.0195 & $(0.0236)$ & 0.0120 & $(0.0188)$ \\
\hline
\end{tabular}

Notes: Robust standard errors in parentheses. Models control for parental education, occupational class, and year of birth. $+p<0.10,{ }^{*} p<0.05$. Source: ONS-LS, (Shelton et al., 2019), own calculations.

Table A11: RDD power estimates with $T=1$ (i.e. effects equal to half the standard deviation of the outcome for the untreated)

\begin{tabular}{lll}
\hline Tau=1 & Female & Male \\
\hline Death at any age & 1 & 1 \\
Death before age 65 & 1 & 1 \\
Lung cancer & 1 & 1 \\
Accident, self-harm & 1 & 1 \\
Liver disease & 1 & 1 \\
Ischaemic heart diseases & 1 & 1 \\
Mental and behavioural & 1 & 1 \\
Preventable & 1 & 1 \\
Long-standing illness 1991 & 1 & 1 \\
Long-standing illness 2001 & 1 & 1 \\
Long-standing illness 2011 & 1 & 1 \\
Poor self-rated health 2001 & 1 & 1 \\
Poor self-rated health 2011 & 1 & 1 \\
\hline
\end{tabular}

Source: ONS-LS, (Shelton et al., 2019), own calculations. 
Table A12: RDD power estimates at varying effect sizes from 'rdpower' in Stata for females

\begin{tabular}{lccc}
\hline & $40 \%$ of an $S D$ & $25 \%$ of an $S D$ & $10 \%$ of an $S D$ \\
\hline Death at any age & 1 & 1 & 0.85 \\
Death before age 65 & 1 & 1 & 0.92 \\
Lung cancer & 1 & 1 & 0.77 \\
Accident, self-harm & 1 & 1 & 0.79 \\
Liver disease & 1 & 1 & 0.65 \\
Ischaemic heart diseases & 1 & 1 & 0.78 \\
Mental and behavioural & 1 & 1 & 0.74 \\
Preventable & 1 & 1 & 0.66 \\
Long-standing illness 1991 & 1 & 1 & 0.72 \\
Long-standing illness 2001 & 1 & 1 & 0.75 \\
Long-standing illness 2011 & 1 & 1 & 0.52 \\
Poor self-rated health 2001 & 1 & 1 & 0.63 \\
Poor self-rated health 2011 & 1 & 1 & 0.66 \\
\hline
\end{tabular}

Source: ONS-LS, (Shelton et al., 2019), own calculations.

Table A13: RDD power estimates at varying effect sizes from 'rdpower' in Stata for males

\begin{tabular}{lccc}
\hline & $40 \%$ of an $S D$ & $25 \%$ of an $S D$ & $10 \%$ of an $S D$ \\
\hline Death at any age & 1 & 1 & 0.83 \\
Death before age 65 & 1 & 1 & 0.87 \\
Lung cancer & 1 & 1 & 0.8 \\
Accident, self-harm & 1 & 1 & 0.85 \\
Liver disease & 1 & 1 & 0.77 \\
Ischaemic heart diseases & 1 & 1 & 0.83 \\
Mental and behavioural & 1 & 1 & 0.69 \\
Preventable & 1 & 1 & 0.71 \\
Long-standing illness 1991 & 1 & 1 & 0.59 \\
Long-standing illness 2001 & 1 & 1 & 0.49 \\
Long-standing illness 2011 & 1 & 0.89 & 0.25 \\
Poor self-rated health 2001 & 1 & 1 & 0.51 \\
Poor self-rated health 2011 & 1 & 0.89 & 0.25 \\
\hline
\end{tabular}

Source: ONS-LS, (Shelton et al., 2019), own calculations. 